\title{
Title: Fast resupply of synaptic vesicles requires Synaptotagmin-3
}

Authors: Dennis J. Weingarten ${ }^{1}$, Amita Shrestha ${ }^{1}$, Sarah A. Kissiwaa ${ }^{1}$, Evan Spruston ${ }^{1}$, and Skyler L. Jackman $^{1 *}$

Affiliations: ${ }^{1}$ Vollum Institute, Oregon Health \& Science University, Portland, OR, USA

*Correspondence to: jackmans@ohsu.edu

Abstract: Sustained neuronal activity demands quick resupply of synaptic vesicles in order to maintain reliable synaptic transmission. Such vesicle replenishment is accelerated by sub-micromolar presynaptic $\mathrm{Ca}^{2+}$ signals by an as yet unidentified high-affinity $\mathrm{Ca}^{2+}$ sensor $^{1-4}$. Here we identify a novel presynaptic role for the high-affinity $\mathrm{Ca}^{2+}$ sensor Synaptotagmin-3 (SYT3) ${ }^{5}$ in driving vesicle replenishment and short-term synaptic plasticity. Synapses in Syt3 knockout mice exhibit enhanced short-term depression, and recovery is slower and insensitive to presynaptic residual $\mathrm{Ca}^{2+}$. During sustained neuronal firing, SYT3 speeds vesicle replenishment and increases the size of the readily releasable pool of vesicles. SYT3 also mediates a second form of short-term enhancement called facilitation, under conditions of low vesicle release probability. Models of vesicle trafficking suggest that SYT3 could combat synaptic depression by accelerating vesicle docking at active zones. Our results reveal a critical role for presynaptic SYT3 in maintaining reliable high-frequency synaptic transmission in neural circuits. 


\section{Main}

Synaptic transmission faces a problem of resource scarcity: neurotransmitter release is limited by the size of the readily releasable pool of vesicles (RRP), which is rapidly depleted by synaptic activity. Vesicle depletion decreases neurotransmitter release, and the fidelity of neuronal signaling. To overcome this problem, a form of short-term plasticity termed $\mathrm{Ca}^{2+}$-dependent recovery from depression (CDR) accelerates vesicle replenishment as synaptic activity increases ${ }^{1-4}$. Although much is understood concerning the mechanisms that traffic and dock vesicles at release sites, the $\mathrm{Ca}^{2+}$ sensor for $\mathrm{CDR}$ has not been identified. Multiple $\mathrm{Ca}^{2+}$-sensing synaptotagmin isoforms regulate vesicle trafficking and fusion ${ }^{6}$. The low-affinity vesicular synaptotagmins SYT1, 2 and 9 serve well-established roles in synchronous vesicle fusion ${ }^{7,8}$, but the functions of other SYT isoforms remain unclear. The high-affinity $\mathrm{Ca}^{2+}$ sensor SYT3 has long been hypothesized to play a role in neurotransmitter release ${ }^{9}$, but SYT3 does not support synaptic transmission from Syt 1 knockout neurons, and thus is not likely to directly drive vesicle fusion ${ }^{8}$. However, SYT3 binds to SNAREs ${ }^{10,11}$, stimulates SNARE-mediated membrane fusion in vitro ${ }^{12}$, and participates in insulin secretion from pancreatic beta cells ${ }^{13,14}$. These observations led to the hypothesis that SYT3 senses sub-micromolar $\mathrm{Ca}^{2+}$ signals to drive short-term plasticity ${ }^{5,9}$. Despite its neuronal abundance and putative roles in neurotransmitter release, SYT3 has no known presynaptic function. Instead, previous studies reported that postsynaptic SYT3 mediates AMPA receptor internalization and longterm depression ${ }^{15,16}$.

\section{SYT3 localizes to both presynaptic and postsynaptic compartments}

Syt3 is expressed broadly throughout the brain, but enriched in the brainstem, cerebellum, and hippocampus ${ }^{17,18}$. Consistent with this expression pattern, we observed strong immunolabeling for SYT3 in the brainstem and cerebellum (Fig. 1a-b). Labeling was absent in Syt3 knockout (KO) mice, confirming antibody specificity (Extended Data Fig. 1). In the brainstem, SYT3 immunolabeling was present in the medial nucleus of the trapezoid body (MNTB) in the region of calyx of Held nerve terminals, and overlapped with the presynaptic marker VGLUT1 (Fig 1a). Consistent with presynaptic expression of SYT3 at the calyx of Held, Syt3 mRNA is present in bushy cells in the ventral cochlear nucleus ${ }^{19}$. In the cerebellum, SYT3 was abundant in the molecular layer (Fig. 1b) where it overlapped with VGLUT1 and VGLUT2, markers for cerebellar parallel fibers and climbing fibers, respectively. However, we could not resolve whether SYT3 immunolabeling is presynaptic or postsynaptic using optical microscopy in brain slices. We next generated synaptosomes from the cerebellum and brainstem (Fig. 1c), and labelled them with antibodies against SYT3, VGLUT1, and the postsynaptic marker PSD-95 (Fig. 1d). Although synaptosomes can contain the presynaptic terminal and postsynaptic fragments $^{20}$, SYT3 labeling was present in nearly all synaptosomes that contained both VGLUT1 and PSD-95, and present in a larger fraction of synaptosomes that were positive for only VGLUT1 compared to only PSD95, suggesting SYT3 may be enriched in presynaptic compartments (Fig. 1e). We also biochemically subfractionated synaptosomes ${ }^{21}$ in order to enrich for presynaptic and postsynaptic compartments (Fig. 1f). Subsequent western blot analysis detected SYT3 in fractions enriched for both compartments (Fig. 1g). These results indicate that SYT3 is present in presynaptic, as well as postsynaptic compartments.

\section{Presynaptic SYT3 is required for $\mathrm{Ca}^{2+}$-dependent recovery from depression}

The calyx of Held is a powerful one-to-one glutamatergic synapse that is highly amenable to quantitative studies of synaptic transmission ${ }^{22,23}$. To measure neurotransmitter release at the calyx of Held, we performed 
whole-cell voltage-clamp recordings in MTNB neurons in acute brain slices from adult (P30-P60) animals (Fig. 2a). Spontaneous excitatory postsynaptic currents (sEPSCs) had similar amplitudes in wildtype (WT) and Syt3 knockout animals (Extended Data Fig. 2), indicating that the loss of SYT3 does not affect postsynaptic receptor density under basal conditions. sEPSC frequency was similar in both genotypes (Extended Data Fig. 2e), suggesting that SYT3 does not affect initial release probability. EPSCs evoked by electrically stimulating presynaptic axons had similar amplitudes and kinetics in WT and Syt3 knockouts, also indicating that SYT3 does not contribute to basal release properties (Extended Data Fig. 2f-g).

To probe short-term plasticity, we stimulated calyces with trains of 100 stimuli. During $1 \mathrm{~Hz}$ stimulation, both genotypes depressed mildly to the same steady-state amplitudes. However, at frequencies $\geq 10 \mathrm{~Hz}$ WT synapses depressed far less than Syt3 knockout synapses (Fig. 2b). As a result, charge transfer (integrated steady-state EPSC amplitudes per second) increased almost linearly as a function of frequency from 10-200 Hz in WT, but not in Syt3 knockouts (Fig. 2c). Enhanced synaptic depression in Syt3 knockout animals could be the indirect result of changes to presynaptic $\mathrm{Ca}^{2+}$ channel expression, or function. Larger presynaptic $\mathrm{Ca}^{2+}$ currents would raise the initial probability of release and accelerate depletion of the RRP, while use-dependent inactivation of $\mathrm{Ca}^{2+}$ channels could reduce release probability during train stimulation. We assessed these possibilities by performing voltage-clamp recordings from presynaptic calyces of young animals (P11-13) ${ }^{24}$. We found that both the amplitudes and use-dependence of $\mathrm{Ca}^{2+}$ currents induced by $1 \mathrm{~ms}$ depolarizations at $100 \mathrm{~Hz}$ were unaltered in KO calyces (Extended Data Fig. 2h-k). Taken together, these data suggest that SYT3 is required to maintain release during high-frequency firing.

At the calyx of Held, CDR plays a critical role in accelerating vesicle replenishment and maintaining neurotransmitter release during high-frequency stimulation. The defining characteristic of CDR is that recovery from depression is slowed when the exogenous $\mathrm{Ca}^{2+}$ buffer EGTA is introduced into presynaptic terminals ${ }^{1,2}$.

We probed recovery from depression at varying intervals after inducing depression with 100 stimuli at $200 \mathrm{~Hz}$. Syt3 knockout synapses recovered with a time constant $\sim 2$-fold slower than WT synapses (Fig. 2e-g). Bath application of $100 \mu \mathrm{M}$ EGTA-AM slowed recovery in WT animals to the degree observed in Syt3 knockouts. In contrast, EGTA-AM had no effect on recovery in Syt3 knockouts (Fig. 2f,g). This indicates that SYT3 is required for $\mathrm{CDR}$ and sustained neurotransmitter release at the calyx of Held.

To determine whether SYT3 affects CDR by acting presynaptically in a cell-autonomous manner, we rescued presynaptic Syt3 expression in knockout animals by injecting a bicistronic adeno-associated viral (AAV) vector into the ventral cochlear nucleus to express SYT3 and GFP. 4-5 weeks after injection, a subset of transduced calyces could be visually identified by GFP fluorescence, and post-hoc immunohistochemistry confirmed the presence of SYT3 in GFP-positive presynaptic terminals (Fig. 3b). GFP/SYT3-positive synapses exhibited reduced depression and a faster recovery, comparable to WT synapses. GFP/SYT3-negative calyces exhibited high-frequency depression, and slow recovery, similar to non-injected Syt3 knockouts (Fig. 3c-e). To determine whether $\mathrm{Ca}^{2+}$ binding by SYT3 is required for CDR, we expressed a $\mathrm{Ca}^{2+}$-binding deficient mutant SYT3 $\left(\mathrm{Syt} 3^{\mathrm{D} / \mathrm{N}}\right) . \mathrm{Syt} 3^{\mathrm{D} / \mathrm{N}}$ expression failed to ameliorate depression or speed recovery from depression. Taken together, these data suggest that CDR requires $\mathrm{Ca}^{2+}$ binding to presynaptic SYT3.

\section{Syt3 increases the readily releasable pool of vesicles}


Presynaptic $\mathrm{Ca}^{2+}$ increases both the rate of vesicle replenishment ${ }^{1}$, and the size of the $\mathrm{RRP}^{25-27}$. To determine whether SYT3 affects the RRP through its role in vesicle replenishment, we used EPSCs driven by $200 \mathrm{~Hz}$ train stimulation to calculate RRP size. We applied multiple, independent methods to estimate RRP size: backextrapolation of cumulative release corrected to account for vesicle replenishment early in the train ${ }^{27}$, a forwardextrapolation method well-suited to estimate the RRP at high frequencies ${ }^{28}$, and an exponential fit of the initial depression within a train ${ }^{29}$. Across all the analysis methods, RRP was significantly increased in WT synapses compared to Syt3 knockout synapses (Extended Data Fig. 3).

Synaptic ultrastructure suggests that vesicles at the active zone exist in two states: tightly docked and lying within $<2 \mathrm{~nm}$ of the plasma membrane, or a loosely docked state further from the membrane $(\sim 5-10 \mathrm{~nm})^{30}$. Tightly docked vesicles are hypothesized to constitute much of the RRP, but loosely docked vesicles may reversibly transition to tight docking and contribute to the RRP ${ }^{31}$. To explore how SYT3 could produce the synaptic properties we observed at the calyx of Held, we constructed models of vesicle docking and fusion. In these models, vesicles are first recruited to a loosely docked state, from which they can reversibly transition to a tightly docked state. Loosely docked vesicles could be refilled by an infinite reserve pool. To minimize the number of free parameters, we purposefully chose the simplest scenario, where only tightly docked vesicles could release, with a uniform release probability. We fit the model to EPSC trains at all frequencies, and recovery from depression using Pearson's $\chi^{2}$ test. After first fitting the model to Syt3 knockout data, we modeled WT synapses by introducing SYT3 as a single, activity-dependent parameter (Extended Data Fig. 4). Models in which SYT3 modulated vesicle release probability of tightly docked vesicles failed to reproduce the behavior of WT synapses. Instead, we found that WT depression and recovery was best fit by a model in which SYT3 increased the transition rate from loose to tight docked states (Extended Data Fig. 4i-j). Such a model is supported by recent evidence for activity-dependent, transient docking of vesicles ${ }^{32}$. In summary, while there is debate as to the identity of vesicles that constitute the RRP, these results show that more vesicles are releasable when SYT3 is present in presynaptic terminals.

\section{Syt3 accelerates vesicle replenishment at multiple synapses}

CDR is also prominent in cerebellar climbing fibers, a powerful glutamatergic synapse onto Purkinje cells ${ }^{2}$. Our immunohistochemistry suggested colocalization of SYT3 with VGLUT2, the presynaptic marker for climbing fibers (Fig. 1b), and Syt3 RNA is expressed in the inferior olive where climbing fibers originate ${ }^{33}$. We performed voltage-clamp recordings from Purkinje cells while electrically stimulating climbing fiber axons in the granule cell layer (Fig. 4a). As with the calyx of Held, we observed no difference in the amplitudes or kinetics of EPSCs between WT and Syt3 knockout climbing fibers, suggesting that SYT3 does not contribute to initial release (Fig. 4b-c). Climbing fibers have a high initial release probability, such that a single stimulus significantly depletes the RRP and causes synaptic depression ${ }^{2}$. CDR can therefore be evaluated by probing recovery at varying interstimulus intervals $(\Delta \mathrm{t})$ after a single, depressing stimulus. Climbing fibers in Syt 3 knockouts exhibited significantly greater depression and recovered $\sim 2$-fold slower than WT synapses (Fig. 4e$\mathrm{f}, \mathrm{i})$. Bath application of $100 \mu \mathrm{M}$ EGTA-AM slowed recovery in WT animals to the degree observed in Syt 3 knockouts. EGTA-AM had no effect on recovery in knockouts (Fig. 4g-i). Another synapse where recovery from depression is slowed by EGTA-AM is the cerebellar mossy fiber-to-granule cell terminal ${ }^{4}$. To test whether SYT3 accelerates vesicle replenishment in mossy fibers, we performed voltage-clamp recordings from cerebellar granule cells and induced synaptic depression with trains of $200 \mathrm{~Hz}$ stimulation and probed the time course of recovery of EPSCs (Extended Data Fig. 5). Similar to calyx of Held and climbing fiber synapses, the 
time-course of recovery from depression was significantly slower in mossy fibers from Syt3 knockouts (WT, $\tau_{\mathrm{W}}$ $=0.66 \pm 0.19 \mathrm{~s} ;$ Syt3 KO, $\tau_{\mathrm{W}}=2.3 \pm 0.59 \mathrm{~s}$ ). Taken together, these results demonstrate that SYT3 is required for $\mathrm{CDR}$ and fast vesicle replenishment in multiple brain regions, at synapses with widely varying release properties.

\section{Syt3 underlies multiple forms of short-term plasticity}

When initial release probability is lowered by decreasing the concentration of extracellular $\mathrm{Ca}^{2+}\left(\left[\mathrm{Ca}^{2+}\right]_{\mathrm{e}}\right)$, cerebellar climbing fibers and the calyx of Held exhibit a second form of short-term plasticity known as facilitation $^{34,35}$. At mammalian synapses, facilitation is primarily driven by SYT7, another high-affinity synaptotagmin isoform ${ }^{36,37}$. However, low $\left[\mathrm{Ca}^{2+}\right]_{\mathrm{e}}$ facilitation persists in $S y t 7$ knockout animals at both the calyx of Held ${ }^{38}$ and climbing fibers ${ }^{39}$. To test the possibility that SYT3 mediates this unexplained form of facilitation, we probed short-term plasticity in low $\left[\mathrm{Ca}^{2+}\right]_{\mathrm{e}}$. As previously reported, WT climbing fibers and calyces exhibited short-lived paired-pulse facilitation (Fig. 5a-c, g-i). However, low $\left[\mathrm{Ca}^{2+}\right]_{\mathrm{e}}$ facilitation was completely absent in Syt3 knockouts. During train stimulation, EPSCs facilitated throughout the train in WT, but not KO synapses (Fig. 5d-f, j-l). This results is somewhat surprising, because CDR and facilitation have traditionally been associated with different mechanisms: CDR is thought to result from accelerated resupply of vesicles, whereas facilitation has been attributed to increased vesicle release probability ${ }^{9,40}$ (although see ${ }^{30}$ ). However, the role of SYT3 in both CDR and facilitation suggests that both forms of short-term plasticity could manifest from the same underlying steps in vesicle trafficking.

\section{Discussion}

Despite decades of study, most synaptotagmin isoforms lack well-defined functions. Here we identify the first role for SYT3 in presynaptic terminals, in accelerating vesicle resupply to sustain robust synaptic transmission. Our results help to explain the observed $\mathrm{Ca}^{2+}$-dependence of vesicle replenishment ${ }^{3}$, recovery from depression ${ }^{1,2}$, and the size of the $\mathrm{RRP}^{27}$. Genetic ablation of Syt3 lead to slow, $\mathrm{Ca}^{2+}$-insensitive vesicle replenishment, without affecting basal release properties or presynaptic $\mathrm{Ca}^{2+}$ currents. Our data are best fit by a biophysical model where $\mathrm{Ca}^{2+}$-bound SYT3 accelerates vesicle docking. SYT3 differs from other synaptotagmin isoforms in its $\mathrm{Ca}^{2+}$-binding properties: It has a high affinity for $\mathrm{Ca}^{2+}$, making it well-suited to sense the sub-micromolar $\mathrm{Ca}^{2+}$ signals that drive $\mathrm{CDR}$ and other forms of short-term plasticity ${ }^{5}$. However, following a drop in $\mathrm{Ca}^{2+}$, SYT3 dissociates from lipid membranes with fast kinetics similar to the low-affinity isoforms SYT1 and $2^{41}$. Thus, SYT3 could respond rapidly to changing $\mathrm{Ca}^{2+}$ levels in order to match vesicle resupply to the demands of ongoing synaptic transmission.

Syt3 is expressed broadly, but heterogeneously, in the mammalian brain ${ }^{17,33}$. In this study we focused on multiple excitatory synapses where $\mathrm{Ca}^{2+}$-dependent vesicle replenishment has been well-characterized. Loss of Syt3 produced similar deficits in synapses despite their widely varied release probabilities, morphology, and in vivo firing patterns, indicating a conserved role in vesicle replenishment. Syt 3 RNA is enriched in inhibitory neurons ${ }^{42}$, suggesting that SYT3 may also sustain the release of GABA, and thereby affect the balance of excitation and inhibition in neural circuits. Consistent with this possibility, Syt 3 mutations have been reported in patients with epilepsy ${ }^{43}$ and autism spectrum disorder ${ }^{44}$. In future studies, cell type-specific removal of $S y t 3$ could reveal how activity-dependent vesicle replenishment contributes to neural circuit function, and neuropsychiatric disease. 


\section{Methods}

No statistical methods were used to predetermine sample size, and experiments were not randomized. Initial electrophysiological recordings at all synapses were performed blind to genotype, but blinding was abandoned after genotypes could be readily identified by physiology. No other blinding was performed.

Animals and viruses. All mice were handled in accordance with NIH guidelines and protocols approved by Oregon Health \& Science University's Institutional Animal Care and Use Committee. Syt3 KO mice were generously provided by Dr. Camin Dean. KO and WT animals of either sex from homozygous or heterozygous breeding pairs (littermates) were used. Viral plasmids were obtained from GenScript with permission from Dr. Camin Dean. AAV9-EGFP-p2A-Syt3 ${ }^{\mathrm{WT}}$ and AAV9-EGFP-p2A-Syt $3^{\mathrm{D} / \mathrm{N}}$ were produced by the Molecular Virology Core at Oregon Health \& Science University. For rescue experiments, 500-900 nl of AAV was injected into P2 animals as previously described ${ }^{45}$. Briefly, animals were anesthetized hypothermically, and virus was injected unilaterally into the left cochlear nucleus. Injection coordinates were (from lambda): $1.4 \mathrm{~mm}$ lateral, $2.7 \mathrm{~mm}$ caudal, $2.9 \mathrm{~mm}$ ventral.

Acute slice preparation. Acute brain slices were prepared from P30-60 animals, except where noted otherwise. Animals were anesthetized with isoflurane and euthanized. Brains were quickly removed into ice-cold cutting solution containing (in $\mathrm{mM}$ ): 125 Choline-Cl, $25 \mathrm{NaHCO}_{3}, 10$ glucose, $2.5 \mathrm{KCl}, 1.25 \mathrm{NaH}_{2} \mathrm{PO}_{4}, 2$ Na-pyruvate, 3 (3)-myo-inositol, 4.4 ascorbic acid, $7 \mathrm{MgCl}_{2}, 0.5 \mathrm{CaCl}_{2}$, bubbled continuously with $95 \% \mathrm{O}_{2} / 5 \% \mathrm{CO}_{2} .270 \mu \mathrm{m}$ thick slices were prepared using a Leica VT1200S vibratome, and transferred to a holding chamber with ACSF containing (in mM): $125 \mathrm{NaCl}, 25 \mathrm{NaHCO}_{3}, 10$ glucose, $2.5 \mathrm{KCl}, 1.25 \mathrm{NaH}_{2} \mathrm{PO}_{4}, 2$ Na-pyruvate, 3 (3)-myoinositol, 4.4 ascorbic acid, $1 \mathrm{MgCl}_{2}, 2 \mathrm{CaCl}_{2}$, bubbled continuously with $95 \% \mathrm{O}_{2} / 5 \% \mathrm{CO}_{2}$. Slices were allowed to recover at $35^{\circ} \mathrm{C}$ for $15 \mathrm{~min}$, then stored at room temperature $\left(24 \pm 1{ }^{\circ} \mathrm{C}\right)$ prior to recording. Climbing fiber and mossy fiber recordings were performed in sagittal cerebellar slices from the vermis. For brainstem recordings slices were cut pseudo-coronally with a $10^{\circ}$ angle towards ventrorostral.

Electrophysiology. Recordings were performed at $34 \pm 0.5^{\circ} \mathrm{C}$, except low $\left[\mathrm{Ca}^{2+}\right]_{\mathrm{e}}$ and presynaptic recordings, which were performed at room temperature to aid comparison with previous studies ${ }^{34,35}$. Slices were continuously perfused with oxygenated ACSF at $\sim 3 \mathrm{ml} / \mathrm{min}$. To isolate AMPAR-driven responses, ACSF contained (in $\mu \mathrm{M}$ ): 100 Picrotoxin, 5 CGP, 1 AM-251, 20 CPP. For MNTB recordings, $0.5 \mu$ M Strychnine was added. For calyx of Held and climbing fiber recordings in $2 \mathrm{mM}\left[\mathrm{Ca}^{2+}\right]_{\mathrm{e}}, 1 \mathrm{mM}$ of kynurenic acid was added to mitigate AMPA receptor saturation ${ }^{22,46}$. Whole-cell recordings were obtained using a EPC10/2 patch-clamp amplifier (HEKA Elektronik). For sEPSC recordings in the MNTB, health of calyces was verified with brief train stimulation. For AAV rescue experiments, GFP-positive calyces were visualized using a Thorlabs M470L2 LED and a Carl Zeiss GFP filter set. For EGTA-AM experiments, 100 $\mu \mathrm{M}$ of EGTA-AM was washed onto slices for 15 min and washed-out for at least 10 minutes prior to recording. MNTB neurons were patched with borosilicate glass electrodes (1.5-2.5 M $\Omega$ ). Cells were voltage-clamped at $-70 \mathrm{mV}$, and bipolar platinum/iridium stimulation electrodes were placed contralaterally around the afferent fiber tract close to the midline. Purkinje cells were patched with 1.2-2 $\mathrm{M} \Omega$ pipettes, held at $-40 \mathrm{mV}$ to inactivate voltage-gated sodium 
channels, and ACSF-filled monopolar glass stimulation electrodes (2-3 M 2 ) were placed in the granule cell layer 50-100 $\mu \mathrm{m}$ from the targeted cell. To ensure no contamination from parallel fiber inputs, stimulation intensity was gradually increased to produce an all-or-none climbing fiber response. For mossy fiber recordings, cerebellar granule cells were patched with 6-8 $\mathrm{M} \Omega$ pipettes, held at $-70 \mathrm{mV}$ and inputs were stimulated in the white matter $100 \mu \mathrm{m}$ from the targeted cell with monopolar glass electrodes. For MNTB and granule cell recordings, the pipette solution contained (in $\mathrm{mM}$ ): $130 \mathrm{Cs}$-gluconate, $10 \mathrm{CsCl}, 5$ EGTA, 10 HEPES, 10 TEACl, 5 Na-phosphocreatine, 4 Mg-ATP, 0.5 Na-GTP, 3 QX-314. For Purkinje cell recordings, the pipette solution contained (in mM): $35 \mathrm{CsF}, 100 \mathrm{CsCl}, 10$ EGTA, 10 HEPES, 5 QX-314. Presynaptic recordings in P11-13 calyces were performed using 7-9 $\mathrm{M} \Omega$ pipettes containing (in $\mathrm{mM}$ ): $130 \mathrm{Cs}$-gluconate, $15 \mathrm{CsCl}, 20 \mathrm{TEA}-\mathrm{Cl}, 5$ Na2-phosphocreatine, 10 HEPES, 0.2 EGTA, 4 ATP-Mg, and 0.5 GTP-Na., and $1 \mu \mathrm{M} \mathrm{TTX,} 10 \mathrm{mM}$ TEA, and $100 \mu \mathrm{M} 4-\mathrm{AP}$ were added to ACSF to isolate $\mathrm{Ca}^{2+}$-currents. Calyces were held at $-80 \mathrm{mV}$ and $1 \mathrm{~ms}$ steps to 0 $\mathrm{mV}$ were used to open voltage-gated $\mathrm{Ca}^{2+}$-channels and elicit tail currents ${ }^{24}$. Data were acquired with a sampling rate of $50 \mathrm{kHz}$, low-pass Bessel-filtered at $2.9 \mathrm{kHz}$, and liquid junction potential was corrected. In MNTB, calyx of Held, and Purkinje cell recordings, series resistance was compensated by at least $80 \%$.

Data in figures represent mean \pm S.E.M.. Paired-pulse responses were fit exponentially, and train responses were fit double-exponentially in IgorPro 8 (Wavemetrics). Stimulation inter-train intervals in all synapses were $30 \mathrm{~s}$. Unless otherwise stated, statistical significance was assessed by initial one-way ANOVA if more than 2 samples were compared. Normal distribution was tested using a single-sample Kolmogorov-Smirnov test. Normally distributed samples were tested for homoscedasticity and compared using unpaired two-tailed Student's t-tests. If one or both samples were not normally distributed, Mann-Whitney u-tests were used instead. All statistical analyses were performed using Microsoft Excel or IgorPro 8.

\section{Modeling}

Biophysical models of synaptic vesicle trafficking and fusion were based on previous studies ${ }^{4,47}$. For simplicity, release was driven by a single pool of tightly docked vesicles $\left(\mathrm{N}^{\mathrm{td}}\right)$, which was refilled from a fusionincompetent loosely docked state $\left(\mathrm{N}^{\mathrm{ld}}\right)^{30}$. Loosely docked vesicles were filled from an infinite reserve pool at a rate $\mathrm{k}_{1}$, and the maximal refill rate was inversely proportional to the fill-state of $\mathrm{N}^{\text {ld }}$. Loosely docked vesicles could return to the reserve pool at a rate $\mathrm{k}_{-1} . \mathrm{N}^{\mathrm{ld}}$ vesicles matured to $\mathrm{N}^{\text {td }}$ at a rate of $\mathrm{k}_{2}$, inversely proportional to the fill-state of $\mathrm{N}^{\text {td }}$, and return to $\mathrm{N}^{\text {ld }}$ with the rate $\mathrm{k}_{-2}$ inversely proportional to its fill-state. Upon stimulation, $\mathrm{N}^{\mathrm{td}}$ vesicles were released with a uniform release probability p. Transition rates between loose and tight docking were described by:

$$
\begin{gathered}
N_{i+1}^{l d}=N_{i}^{l d}+k_{1} * \frac{N_{i}^{l d}}{N_{\text {max }}^{l d}}-k_{-1} * N_{i}^{l d}-k_{2} * N_{i}^{l d} * \frac{N_{i}^{t d}}{N_{\max }^{t d}}+k_{-2} * N_{i}^{t d} * \frac{N_{i}^{l d}}{N_{\text {max }}^{l d}} \\
N_{i+1}^{t d}=N_{i}^{t d}+k_{2} * N_{i}^{l d} * \frac{N_{i}^{t d}}{N_{\text {max }}^{t d}}-k_{-2} * N_{i}^{t d} * \frac{N_{i}^{l d}}{N_{\max }^{l d}}-N_{i}^{t d} * p
\end{gathered}
$$

$20 \mathrm{~s}$ of inactivity were simulated before each stimulation pattern to allow fill-states to reach equilibrium. In the model where SYT3 drove a transient increase in release probability, $\mathrm{p}$ was described by: 


$$
p_{i+1}=p_{i}-\frac{\left(p_{i}-p_{0}\right)}{\tau_{S Y T 3}}+p_{S Y T 3} *\left(1-p_{i}\right)
$$

In the models where SYT3 transiently increased $\mathrm{k}_{1}$ or $\mathrm{k}_{2}$, they were described by:

$$
k_{i+1}=k_{i}-\frac{\left(k_{i}-k_{0}\right)}{\tau_{S Y T 3}}+k_{S Y T 3}
$$

Best fits to experimental KO data were performed using Pearson's $\chi^{2}$ tests across all frequency trains $(1 \mathrm{~Hz}, 10$ $\mathrm{Hz}, 20 \mathrm{~Hz}, 50 \mathrm{~Hz}, 100 \mathrm{~Hz}, 200 \mathrm{~Hz}$ ) and recovery from depression after $200 \mathrm{~Hz}$. These parameters were then fixed, and WT experimental data were subsequently fit by introducing parameters representing a putative SYT3 contribution. Baseline sampling rate was $1 \mathrm{~ms}$, and lowering it to $100 \mu \mathrm{s}$ only marginally changed the best fit parameters. All modeling and fitting were performed with custom IgorPro 8 functions.

\section{Immunohistochemistry}

Mice were anaesthetized with ketamine/xylazine $(100 / 10 \mathrm{mg} / \mathrm{kg})$ and transcardially perfused with $4 \%$ paraformaldehyde (PFA) in PBS. Brains were removed and post-fixed overnight at $4{ }^{\circ} \mathrm{C} .50 \mu \mathrm{m}$ slices were prepared using a Leica VT1000S vibratome, and permeabilized for $1 \mathrm{~h}$ in vehicle (PBS, 10\% normal goat serum, $0.3 \%$ Triton $\mathrm{X}-100$ ), then incubated overnight at $4{ }^{\circ} \mathrm{C}$ in vehicle with primary antibodies (rabbit antiSyt3, 1:500, Synaptic Systems 105133; guinea pig anti-vGlut1, 1:500, Synaptic Systems 135304; guinea pig anti-vGlut2, 1:500, Synaptic Systems 135404). After 4 washes for 5 minutes in vehicle, slices were incubated with secondary antibodies in vehicle for $2 \mathrm{~h}$ at room temperature (goat-anti-rabbit Alexa 546, 1:500, ThermoFisher A-11035; goat-anti-guinea pig CF633, 1:400, Biotum 20129). After 4 washes in PBS, slices were mounted in Prolong Gold. Images were acquired using either Zeiss AxioImager (low magnification) or Zeiss Elyra 7 (airyscan). For each brain region, images from WT and KO animals were acquired using the same microscope settings, and processed in ImageJ identically.

\section{Synaptosome preparation}

6 mice were euthanized, and the brainstem and cerebellum were dissected in ice-cold ACSF. Pooled tissue from each brain region was suspended in $6 \mathrm{ml}$ of $0.32 \mathrm{M}$ sucrose homogenization buffer (4 mM HEPES, $0.1 \mathrm{mM}$ $\mathrm{CaCl}_{2}, 1 \mathrm{mM} \mathrm{MgCl}$, plus Roche protease inhibitor tablet) and homogenized with a Teflon homogenizer using 10 strokes at $900 \mathrm{rpm}$. Nuclear material was removed by centrifuging at $1000 \mathrm{~g}$ for $10 \mathrm{mins}$ at $4{ }^{\circ} \mathrm{C}$. The supernatant was collected and centrifuged at $17,500 \mathrm{~g}$ for $15 \mathrm{~min}$ at $4{ }^{\circ} \mathrm{C}$. The pellet was suspended in $2.5 \mathrm{ml}$ of homogenization buffer, and homogenized with manually with 6 strokes. The homogenate was brought to 1.25 $\mathrm{M}$ sucrose by addition of $12 \mathrm{ml}$ of $2 \mathrm{M}$ sucrose homogenization buffer, and $5 \mathrm{ml}$ of $0.1 \mathrm{mM} \mathrm{CaCl}_{2}$, then divided into 2 ultracentrifuge tubes and carefully overlaid with $2.5 \mathrm{ml}$ of $1 \mathrm{M}$ sucrose homogenization buffer. The gradient was centrifuged at $100,000 \mathrm{~g}$ for $3 \mathrm{~h}$ at $4{ }^{\circ} \mathrm{C}$. The hazy layer of synaptosomes was collected from the 1/1.25 $\mathrm{M}$ sucrose interphase, and diluted 1:10 with $0.32 \mathrm{M}$ sucrose homogenization buffer, and centrifuged at $20,000 \mathrm{~g}$ for $30 \mathrm{~min}$ at $4{ }^{\circ} \mathrm{C}$. The pellet (synaptosomes) was resuspended with $2 \mathrm{ml}$ of $0.32 \mathrm{M}$ sucrose homogenization buffer. For western blots, $100 \mu \mathrm{l}$ of synaptosomes were centrifuged at $11,000 \mathrm{~g}$ for $11 \mathrm{mins}$, and the pellet resuspended in 5\% SDS. $50 \mu 1$ of aliquoted synaptosomes were stored at $-80{ }^{\circ} \mathrm{C}$ for immunostaining, and the remainder was used for biochemical fractionation. 
Biochemical fractionation of synaptosomes was performed as previously described ${ }^{21}$ with minor modifications. Purified synaptosomes were lysed osmotically by addition of $5 \mathrm{ml}$ of $0.1 \mathrm{mM} \mathrm{CaCl}_{2}$ and homogenized with 3 strokes at $2000 \mathrm{rpm} .5 \mathrm{ml} 20 \mathrm{mM}$ MES (pH 6.0) was added and the mixture was incubated on ice for $30 \mathrm{~min}$, then centrifuged at 40,000 $\mathrm{g}$ for $30 \mathrm{~min}$. The resulting supernatant, considered to be the vesicle-rich fraction, was acetone precipitated and centrifuged at $18,000 \mathrm{~g}$ at $4{ }^{\circ} \mathrm{C}$ for $30 \mathrm{~min}$ to collect synaptic vesicle proteins. The pellet, containing presynaptic and postsynaptic membranes, was washed with $20 \mathrm{mM}$ Tris- $\mathrm{HCl}, \mathrm{pH} 8.0,1 \%$ Triton X-100, $0.1 \mathrm{mM} \mathrm{CaCl}_{2}$, resuspended and centrifuged at 201,000 $\mathrm{g}$ to collect the postsynaptic fraction. The supernatant was acetone precipitated overnight to obtain the presynaptic fraction. Samples were stored at $-80{ }^{\circ} \mathrm{C}$ until processed for western blotting.

\section{Western blotting of synaptosomes}

Protein concentration was quantified using a BCA assay (Pierce). $1 \mu \mathrm{g}$ of each fraction was loaded in $10 \%$ SDS-PAGE gel and transferred to PVDF membrane (Millipore Sigma). Membranes were incubated in blocking solution for $1 \mathrm{~h}$ at RT (3\% BSA, 0.1\% Tween-20), then in primary antibody for $2 \mathrm{~h}$ at RT (rabbit anti-Syt3, 1:3000, Synaptic Systems 105133; rabbit anti-Synaptophysin, 1:4000, Proteintech 17785; mouse anti-Syntaxin, 1:3000, Proteintech 66437; guinea pig anti-PSD-95, 1:3000, Synaptic Systems 124014). Membranes were rinsed with TBS and incubated in HRP-conjugated secondary antibodies for $90 \mathrm{~min}$ at RT (All Proteintech 1:5000: goat anti-rabbit, SA00001-2; goat anti-guinea pig, SA00001-12; goat anti-mouse, SA00001-1). Membranes were developed in chemiluminescent substrate (Supersignal West Pico Plus, Thermofisher) for 2 min, and imaged using a Biorad ChemiDoc system.

\section{Immunostaining of synaptosomes}

Frozen aliquots were thawed and diluted with $0.32 \mathrm{M}$ sucrose. Diluted synaptosomes were spun down on polyD-lysine coated coverslips (Neuvitro) at $3000 \mathrm{~g}$ for $15 \mathrm{~min}$ at $4{ }^{\circ} \mathrm{C}$. Plated synaptosomes were fixed with $4 \%$ PFA for $30 \mathrm{~min}$ at RT, and washed in PBS. Samples were permeabilized in PBS + 0.25\% Triton X-100 for 10 min at RT. After blocking in $20 \%$ normal goat serum for $30 \mathrm{~min}$ at RT, plated synaptosomes were incubated in primary antibody with PBS, 5\% normal goat serum, 0.1\% Triton X-100 for 90 min at RT (see antibodies above, Syt3 1:2000; VGLUT1 1:2000; VGLUT2 1:2000; PSD-95, 1:1000). After washing in 5\% normal goat serum, $0.25 \%$ Triton X-100, samples were incubated in PBS, $5 \%$ normal goat serum, $0.1 \%$ Triton X-100 secondary antibody for 60 minutes at RT (goat-anti-rabbit Alexa 546, 1:500, ThermoFisher A-11035; goat-anti-guinea pig CF633, 1:500, Biotum 20129; goat anti-mouse Alexa 488, 1:1000, ThermoFisher A-11001). Samples were mounted in ProLong Gold Antifade (Life Technologies) and the images were acquired using a Zeiss Axioimager phase-contrast microscope. 


\section{Acknowledgements}

We thank C. Dean for providing Syt3 knockout mice and viral plasmids; the OHSU Molecular Virology Core for packaging AAV vectors; K. Wright, K. Monk, S. Kaech Petrie and the Advanced Imaging Core for microscopy assistance; G. Westbrook, H. von Gersdorff, L. Trussell, M. Freeman, and P. Brehm for comments on the manuscript; P. Kaeser and myriad generous Vollum colleagues for reagents, technical assistance, and helpful discussions.

\section{Contributions}

D.J.W., A.S., and S.L.J. conceived of and designed the study. D.J.W. performed all electrophysiological recordings and analyses. S.K. and S.L.J. performed histology and imaging. D.J.W. and E.S. performed biophysical modeling and data fitting. D.J.W. and S.L.J. wrote the manuscript with input from all authors.

\section{Competing interests}

The authors have no competing interests to declare.

\section{Materials \& Correspondence}

Correspondence and requests for materials should be addressed to: 3181 SW Sam Jackson Park Rd., Portland, OR 97239, USA. E-mail: jackmans@ @ohsu.edu, Telephone: 503-494-3295 


\section{References}

1 Wang, L. Y. \& Kaczmarek, L. K. High-frequency firing helps replenish the readily releasable pool of synaptic vesicles. Nature 394, 384-388, doi:10.1038/28645 (1998).

Dittman, J. S. \& Regehr, W. G. Calcium Dependence and Recovery Kinetics of Presynaptic Depression at the Climbing Fiber to Purkinje Cell Synapse. The Journal of Neuroscience 18, 6147-6162, doi:10.1523/jneurosci.18-16-06147.1998 (1998).

3 Stevens, C. F. \& Wesseling, J. F. Identification of a Novel Process Limiting the Rate of Synaptic Vesicle Cycling at Hippocampal Synapses. Neuron 24, 1017-1028, doi:10.1016/s0896-6273(00)81047-8 (1999).

Ritzau-Jost, A. et al. Apparent calcium dependence of vesicle recruitment. J Physiol 596, 4693-4707, doi:10.1113/JP275911 (2018). exocytotic $\mathrm{Ca}(2+)$ sensors with distinct $\mathrm{Ca}(2+)$ affinities. EMBO J 21, 270-280, doi:10.1093/emboj/21.3.270 (2002).

6 Sudhof, T. C. Synaptotagmins: why so many? J Biol Chem 277, 7629-7632, doi:10.1074/jbc.R100052200 (2002).

7 Littleton, J. T. \& Bellen, H. J. Synaptotagmin controls and modulates synaptic-vesicle fusion in a Ca2+dependent manner. Trends in Neurosciences 18, 177-183, doi:10.1016/0166-2236(95)93898-8 (1995).

8 Xu, J., Mashimo, T. \& Südhof, T. C. Synaptotagmin-1, -2, and -9: $\mathrm{Ca}(2+)$ sensors for fast release that specify distinct presynaptic properties in subsets of neurons. Neuron 54, 567-581, doi:10.1016/j.neuron.2007.05.004 (2007).

9 Zucker, R. S. \& Regehr, W. G. Short-term synaptic plasticity. Annu Rev Physiol 64, 355-405, doi:10.1146/annurev.physiol.64.092501.114547 (2002). 
10 Sutton, R. B., Ernst, J. A. \& Brunger, A. T. Crystal Structure of the Cytosolic C2a-C2b Domains of Synaptotagmin III. Journal of Cell Biology 147, 589-598, doi:10.1083/jcb.147.3.589 (1999).

11 Vrljic, M. et al. Molecular mechanism of the synaptotagmin-SNARE interaction in Ca2+-triggered vesicle fusion. Nature Structural \& Molecular Biology 17, 325-331, doi:10.1038/nsmb.1764 (2010).

12 Bhalla, A., Chicka, M. C. \& Chapman, E. R. Analysis of the Synaptotagmin Family during

Reconstituted Membrane Fusion. Journal of Biological Chemistry 283, 21799-21807, doi:10.1074/jbc.m709628200 (2008).

13 Mizuta, M. et al. Localization and functional role of synaptotagmin III in insulin secretory vesicles in pancreatic beta-cells. Diabetes 46, 2002-2006, doi:10.2337/diab.46.12.2002 (1997).

14 Gao, Z., Reavey-Cantwell, J., Young, R. A., Jegier, P. \& Wolf, B. A. Synaptotagmin III/VII Isoforms Mediate Ca2+-induced Insulin Secretion in Pancreatic Islet $\beta$-Cells. Journal of Biological Chemistry 275, 36079-36085, doi:10.1074/jbc.m004284200 (2000).

15 Dean, C. et al. Axonal and dendritic synaptotagmin isoforms revealed by a pHluorin-syt functional screen. Mol Biol Cell 23, 1715-1727, doi:10.1091/mbc.E11-08-0707 (2012).

16 Awasthi, A. et al. Synaptotagmin-3 drives AMPA receptor endocytosis, depression of synapse strength, and forgetting. Science 363, doi:10.1126/science.aav1483 (2019).

17 Hilbush, B. S. \& Morgan, J. I. A third synaptotagmin gene, Syt3, in the mouse. Proceedings of the National Academy of Sciences 91, 8195-8199, doi:10.1073/pnas.91.17.8195 (1994).

18 Butz, S., Fernandez-Chacon, R., Schmitz, F., Jahn, R. \& Sudhof, T. C. The subcellular localizations of atypical synaptotagmins III and VI. Synaptotagmin III is enriched in synapses and synaptic plasma membranes but not in synaptic vesicles. J Biol Chem 274, 18290-18296, doi:10.1074/jbc.274.26.18290 (1999).

19 Xiao, L. et al. Developmental expression of Synaptotagmin isoforms in single calyx of Held-generating neurons. Mol Cell Neurosci 44, 374-385, doi:10.1016/j.mcn.2010.05.002 (2010). 
20 Whittaker, V. P. Thirty years of synaptosome research. Journal of Neurocytology 22, 735-742, doi:10.1007/bf01181319 (1993).

21 Phillips, G. R. et al. The Presynaptic Particle Web. Neuron 32, 63-77, doi:10.1016/s08966273(01)00450-0 (2001).

22 Sakaba, T. \& Neher, E. Calmodulin Mediates Rapid Recruitment of Fast-Releasing Synaptic Vesicles at a Calyx-Type Synapse. Neuron 32, 1119-1131, doi:10.1016/s0896-6273(01)00543-8 (2001).

23 Chen, Z., Cooper, B., Kalla, S., Varoqueaux, F. \& Young, S. M., Jr. The Munc13 proteins differentially regulate readily releasable pool dynamics and calcium-dependent recovery at a central synapse. $J$ Neurosci 33, 8336-8351, doi:10.1523/JNEUROSCI.5128-12.2013 (2013).

24 Taschenberger, H., Leao, R. M., Rowland, K. C., Spirou, G. A. \& von Gersdorff, H. Optimizing synaptic architecture and efficiency for high-frequency transmission. Neuron 36, 1127-1143, doi:10.1016/s0896-6273(02)01137-6 (2002).

25 Schneggenburger, R., Meyer, A. C. \& Neher, E. Released Fraction and Total Size of a Pool of Immediately Available Transmitter Quanta at a Calyx Synapse. Neuron 23, 399-409, doi:10.1016/s0896-6273(00)80789-8 (1999).

26 Taschenberger, H. \& von Gersdorff, H. Fine-Tuning an Auditory Synapse for Speed and Fidelity: Developmental Changes in Presynaptic Waveform, EPSC Kinetics, and Synaptic Plasticity. The Journal of Neuroscience 20, 9162-9173, doi:10.1523/jneurosci.20-24-09162.2000 (2000).

27 Thanawala, M. S. \& Regehr, W. G. Presynaptic calcium influx controls neurotransmitter release in part by regulating the effective size of the readily releasable pool. J Neurosci 33, 4625-4633, doi:10.1523/JNEUROSCI.4031-12.2013 (2013).

28 Elmqvist, D. \& Quastel, D. M. A quantitative study of end-plate potentials in isolated human muscle. J Physiol 178, 505-529, doi:10.1113/jphysiol.1965.sp007639 (1965).

29 Thanawala, M. S. \& Regehr, W. G. Determining synaptic parameters using high-frequency activation. $J$ Neurosci Methods 264, 136-152, doi:10.1016/j.jneumeth.2016.02.021 (2016). 
30 Neher, E. \& Brose, N. Dynamically Primed Synaptic Vesicle States: Key to Understand Synaptic ShortTerm Plasticity. Neuron 100, 1283-1291, doi:10.1016/j.neuron.2018.11.024 (2018).

31 Kaeser, P. S. \& Regehr, W. G. The readily releasable pool of synaptic vesicles. Curr Opin Neurobiol 43, 63-70, doi:10.1016/j.conb.2016.12.012 (2017).

32 Kusick, G. F. et al. Synaptic vesicles transiently dock to refill release sites. Nature Neuroscience 23, 1329-1338, doi:10.1038/s41593-020-00716-1 (2020).

33 Lein, E. S. et al. Genome-wide atlas of gene expression in the adult mouse brain. Nature 445, 168-176, doi:10.1038/nature05453 (2007).

34 Muller, M., Felmy, F., Schwaller, B. \& Schneggenburger, R. Parvalbumin is a mobile presynaptic Ca2+ buffer in the calyx of Held that accelerates the decay of Ca2+ and short-term facilitation. J Neurosci 27, 2261-2271, doi:10.1523/JNEUROSCI.5582-06.2007 (2007).

35 Foster, K. A., Kreitzer, A. C. \& Regehr, W. G. Interaction of Postsynaptic Receptor Saturation with Presynaptic Mechanisms Produces a Reliable Synapse. Neuron 36, 1115-1126, doi:10.1016/s08966273(02)01106-6 (2002).

36 Jackman, S. L., Turecek, J., Belinsky, J. E. \& Regehr, W. G. The calcium sensor synaptotagmin 7 is required for synaptic facilitation. Nature 529, 88-91, doi:10.1038/nature16507 (2016).

37 Chen, C., Satterfield, R., Young, S. M., Jr. \& Jonas, P. Triple Function of Synaptotagmin 7 Ensures Efficiency of High-Frequency Transmission at Central GABAergic Synapses. Cell Rep 21, 2082-2089, doi:10.1016/j.celrep.2017.10.122 (2017).

38 Luo, F. \& Südhof, T. C. Synaptotagmin-7-Mediated Asynchronous Release Boosts High-Fidelity Synchronous Transmission at a Central Synapse. Neuron 94, 826-839.e823, doi:10.1016/j.neuron.2017.04.020 (2017).

39 Weyrer, C. Molecular Mechanisms of Presynaptic Plasticity and Function in the Mammalian Brain Doctor of Philosophy (PhD) thesis, University of Camebridge, (2018). 
40 Jackman, S. L. \& Regehr, W. G. The Mechanisms and Functions of Synaptic Facilitation. Neuron 94, 447-464, doi:10.1016/j.neuron.2017.02.047 (2017).

41 Hui, E. et al. Three distinct kinetic groupings of the synaptotagmin family: candidate sensors for rapid and delayed exocytosis. Proc Natl Acad Sci U S A 102, 5210-5214, doi:10.1073/pnas.0500941102 (2005).

42 Saunders, A. et al. Molecular diversity and specializations among the cells of the adult mouse brain. Cell 174, 1015-1030. e1016 (2018).

43 Dimassi, S. et al. A subset of genomic alterations detected in rolandic epilepsies contains candidate or known epilepsy genes including GRIN 2A and PRRT 2. Epilepsia 55, 370-378 (2014).

44 Sato, D. et al. SHANK1 deletions in males with autism spectrum disorder. The American Journal of Human Genetics 90, 879-887 (2012).

45 Pilpel, N., Landeck, N., Klugmann, M., Seeburg, P. H. \& Schwarz, M. K. Rapid, reproducible transduction of select forebrain regions by targeted recombinant virus injection into the neonatal mouse brain. Journal of Neuroscience Methods 182, 55-63, doi:10.1016/j.jneumeth.2009.05.020 (2009).

46 Wadiche, J. I. \& Jahr, C. E. Multivesicular release at climbing fiber-Purkinje cell synapses. Neuron 32, 301-313, doi:10.1016/s0896-6273(01)00488-3 (2001).

47 Hallermann, S. et al. Bassoon speeds vesicle reloading at a central excitatory synapse. Neuron 68, $710-$ 723, doi:10.1016/j.neuron.2010.10.026 (2010).

48 Guan, Z., Quinones-Frias, M. C., Akbergenova, Y. \& Littleton, J. T. Drosophila Synaptotagmin 7 negatively regulates synaptic vesicle release and replenishment in a dosage-dependent manner. Elife $\mathbf{9}$, doi:10.7554/eLife.55443 (2020). 


\section{Figures}

Figure 1 | SYT3 is localized to presynaptic terminals.

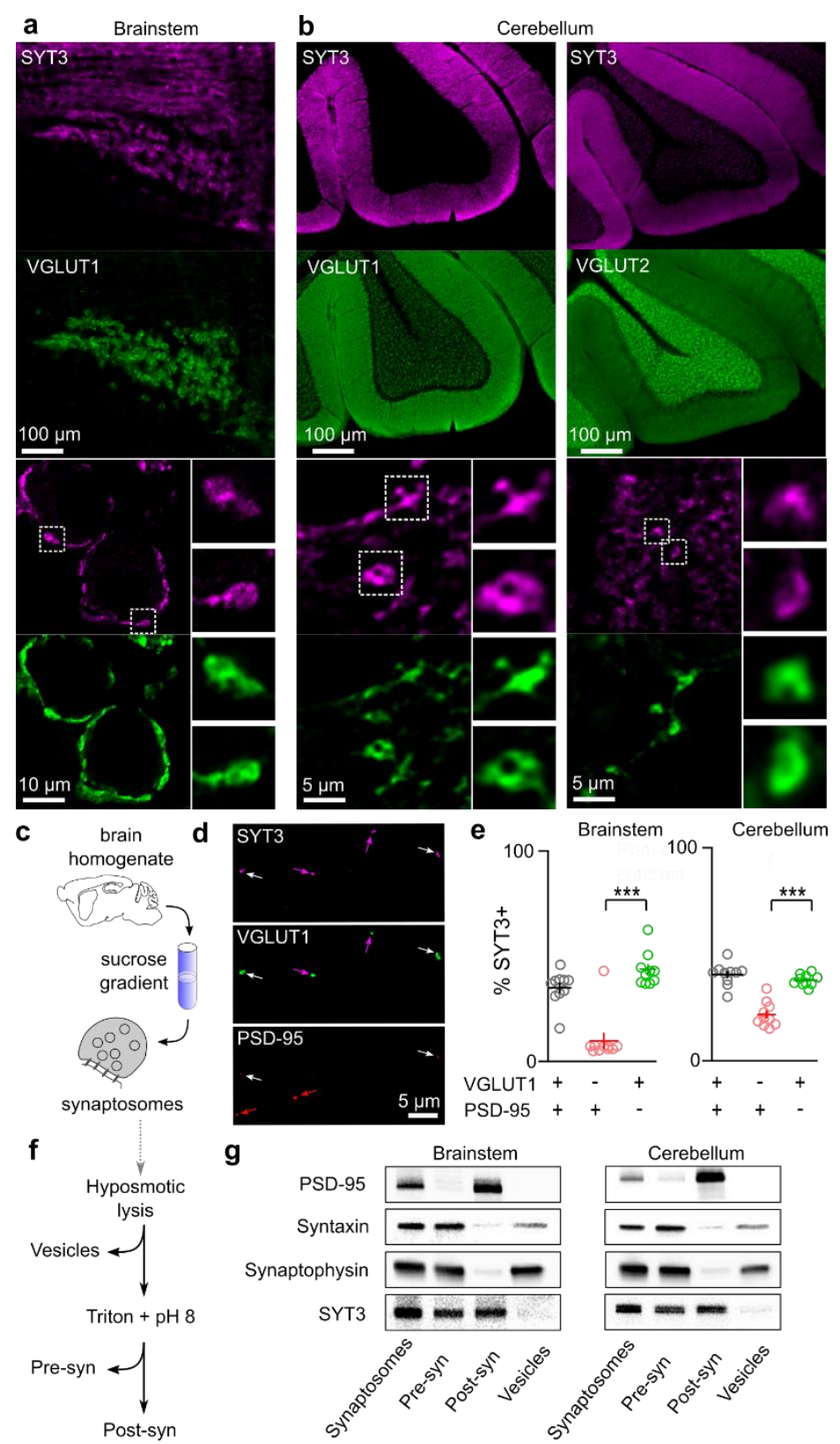

a) Immunolabeling for SYT3 and VGLUT1 in the MNTB (top), and high-magnification airyscan images showing calyces of Held (bottom).

b) Immunolabeling for SYT3, and VGLUT1 (left) or VGLUT2 (right) and in the cerebellum (top), and airyscan images in the molecular layer (bottom).

c) Schematic showing synaptosome preparation.

d) Synaptosomes isolated from brainstem homogenate, immunolabeled for SYT3, VGLUT1 and PSD-95. Arrows indicate synaptosomes labeled for SYT3/PSD-95/VGLUT1 (white), SYT3/VGLUT1(magenta), and PSD-95 only (red).

e) Distribution of SYT3-positive synaptosomes that overlapped with VGLUT1 and/or PSD-95. 
f) Schematic showing synaptosome sub-fractionation.

g) Western blots from biochemically fractionated synaptosomes from brainstem and cerebellar tissue. Blots were immunostained for PSD-95 (postsynaptic), Syntaxin-1A/B (presynaptic), Synaptophysin (vesicles), and SYT3.

Data in all figures represent mean \pm S.E.M. Number of experiments for each experiment are shown in Extended Data Table 1. Statistical significance was tested (Student's $t$-test) after normal distribution and homoscedasticity were confirmed. For multiple comparisons, critical significance thresholds were post-hoc Bonferroni corrected. Significances are shown as $*: p<0.05, * *: p<0.01, * * *: p<0.001$ 
Figure 2 | Syt3 accelerates vesicle resupply at the calyx of Held

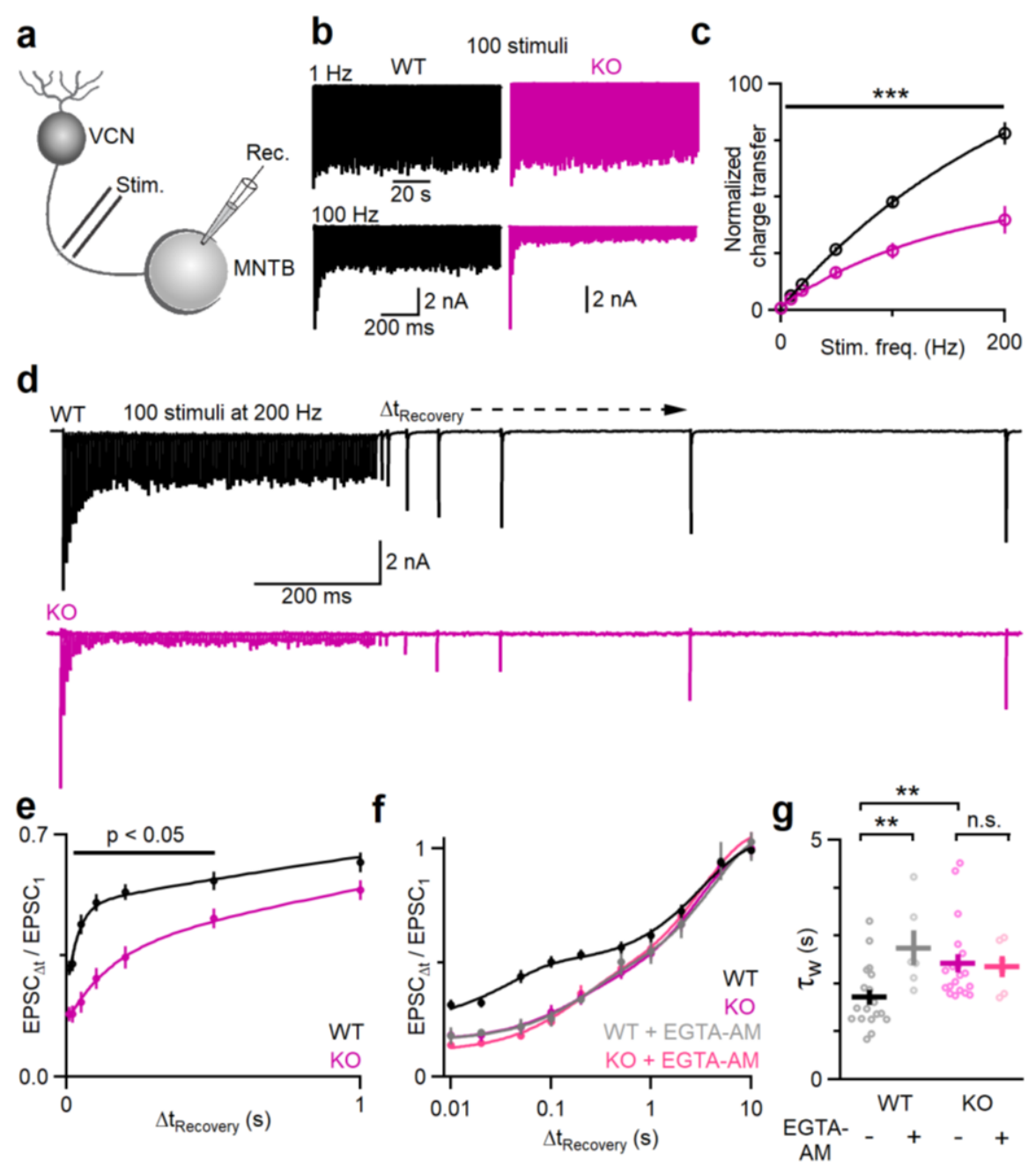

a) Schematic for calyx of Held recordings. EPSCs were recorded in MNTB neurons while presynaptic axons originating from globular bushy cells in the ventral cochlear nucleus (VCN) were activated by extracellular electrical stimulation.

b) EPSCs elicited by 100 stimuli at $1 \mathrm{~Hz}$ and $100 \mathrm{~Hz}$ in WT (black) and KO (magenta) animals.

c) Averaged charge transfer of EPSC $81-100$ for different stimulation frequencies, normalized to EPSC $_{1}$

d) Representative EPSCs elicited by 100 stimuli at 200, followed by stimuli at varying intervals to probe recovery from depression $\left(\Delta t_{\text {Recovery }}\right)$

e) First second of recovery of EPSCs after $200 \mathrm{~Hz}$ stimulation, fit with biexponential curves.

f) Full time-course of recovery of EPSCs after $200 \mathrm{~Hz}$ stimulation in control ACSF (WT: black, KO: magenta) and after EGTA-AM treatment (WT: gray, KO: light magenta).

g) Weighted time constant of biexponential recovery $\left(\tau_{\mathrm{w}}\right)$ for all groups. 
Figure 3 | Recovery from depression is accelerated by $\mathrm{Ca}^{2+}$ binding to presynaptic SYT3

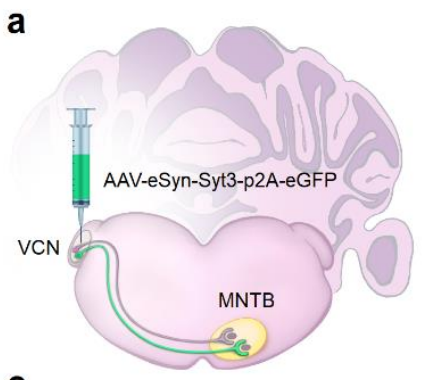

b

C
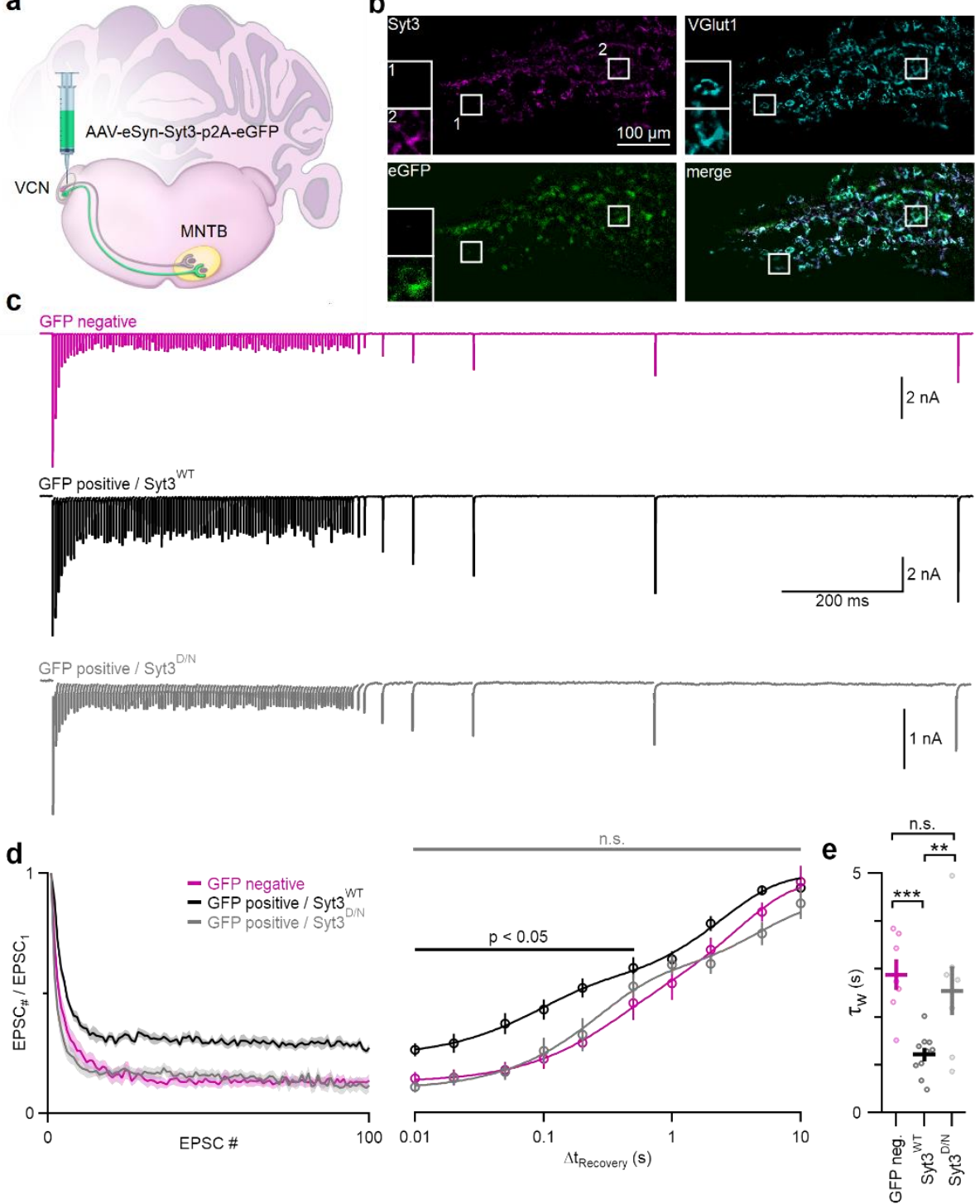

a) Schematic of viral Syt3 rescue injections. A bicistronic AAV vector was injected into the VCN of $S y t 3 \mathrm{KOs}$ to express GFP, along with either wildtype SYT3 (Syt3 $\left.{ }^{\mathrm{WT}}\right)$, or $\mathrm{Ca}^{2+}$-binding deficient SYT3 $\left(\mathrm{Syt}^{\mathrm{D} / \mathrm{N}}\right)$.

b) Fluorescent images of immunostaining for VGLUT1 and SYT3, and GFP fluorescence in the MNTB of a Syt3 KO animal after viral injection.

c) Representative EPSCs from GFP-positive calyces expressing Syt3 ${ }^{\mathrm{WT}}$ (black), Syt3 ${ }^{\mathrm{D} / \mathrm{N}}$ (gray), and GFPnegative (magenta) calyces elicited by 100 stimuli at $200 \mathrm{~Hz}$, followed by stimuli at varying intervals to probe recovery from depression $\left(\Delta t_{\text {Recovery }}\right)$.

d) Average normalized EPSC amplitudes during train stimulation and subsequent recovery. Bars indicate statistical significance between GFP-negative synapses and Syt $3^{\mathrm{WT}}$-expressing (black), or Syt $3^{\mathrm{D} / \mathrm{N}}$-expressing synapses (gray).

e) Weighted time constants of biexponential recovery for all groups $\left(\tau_{\mathrm{w}}\right)$. 
Figure 4 | Syt3 accelerates recovery from depression in cerebellar climbing fibers
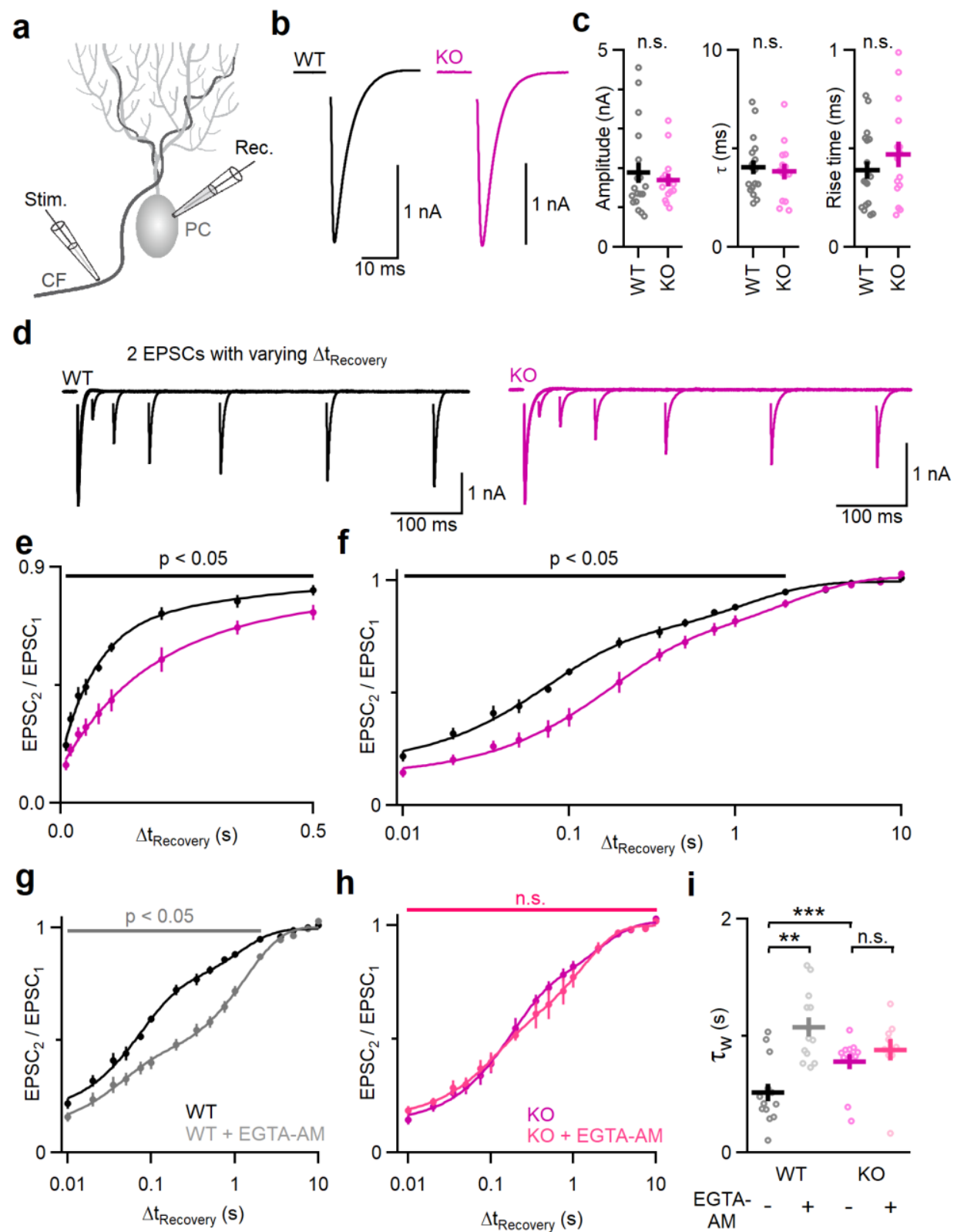

h
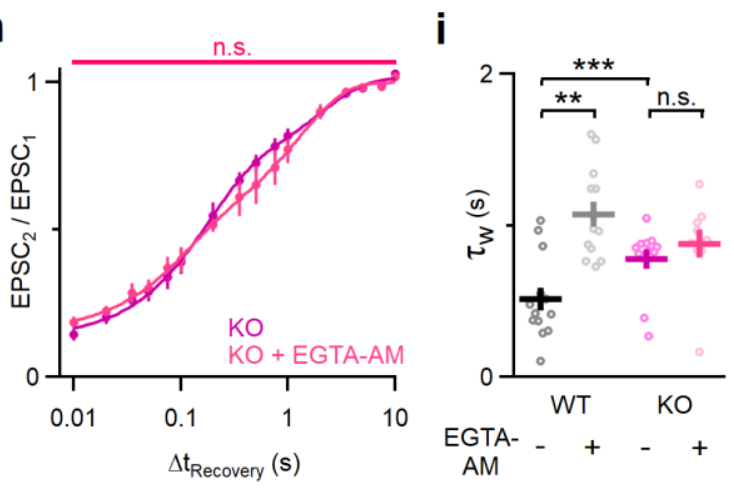

a) Schematic of cerebellar climbing fiber recordings. EPSCs were recorded from voltage-clamped Purkinje cells (PCs), while climbing fibers (CF) were activated by electrical stimulation in the granule cell layer.

b) Representative EPSCs in Purkinje cells elicited by climbing fiber stimulation in WT (black) and KO (magenta) animals.

c) Average EPSC amplitude, $20-80 \%$ rise time, and exponential decay time constant $\left(\tau_{\text {Decay }}\right)$.

d) Superimposed recordings of EPSCs evoked by pairs of stimuli of climbing fiber synapses with varying

$\Delta$ tRecovery

e-f) Time-course of recovery from depression in linear (e) and logarithmic scale (f).

g-h) Recovery in WT (g) and Syt3 KO (h) in control ACSF and after EGTA-AM treatment.

i) Weighted time constant of biexponential recovery $\left(\tau_{\mathrm{w}}\right)$ for all groups. 
Figure 5 | SYT3 drives facilitation at depressing synapses in low extracellular $\mathrm{Ca}^{2+}$.
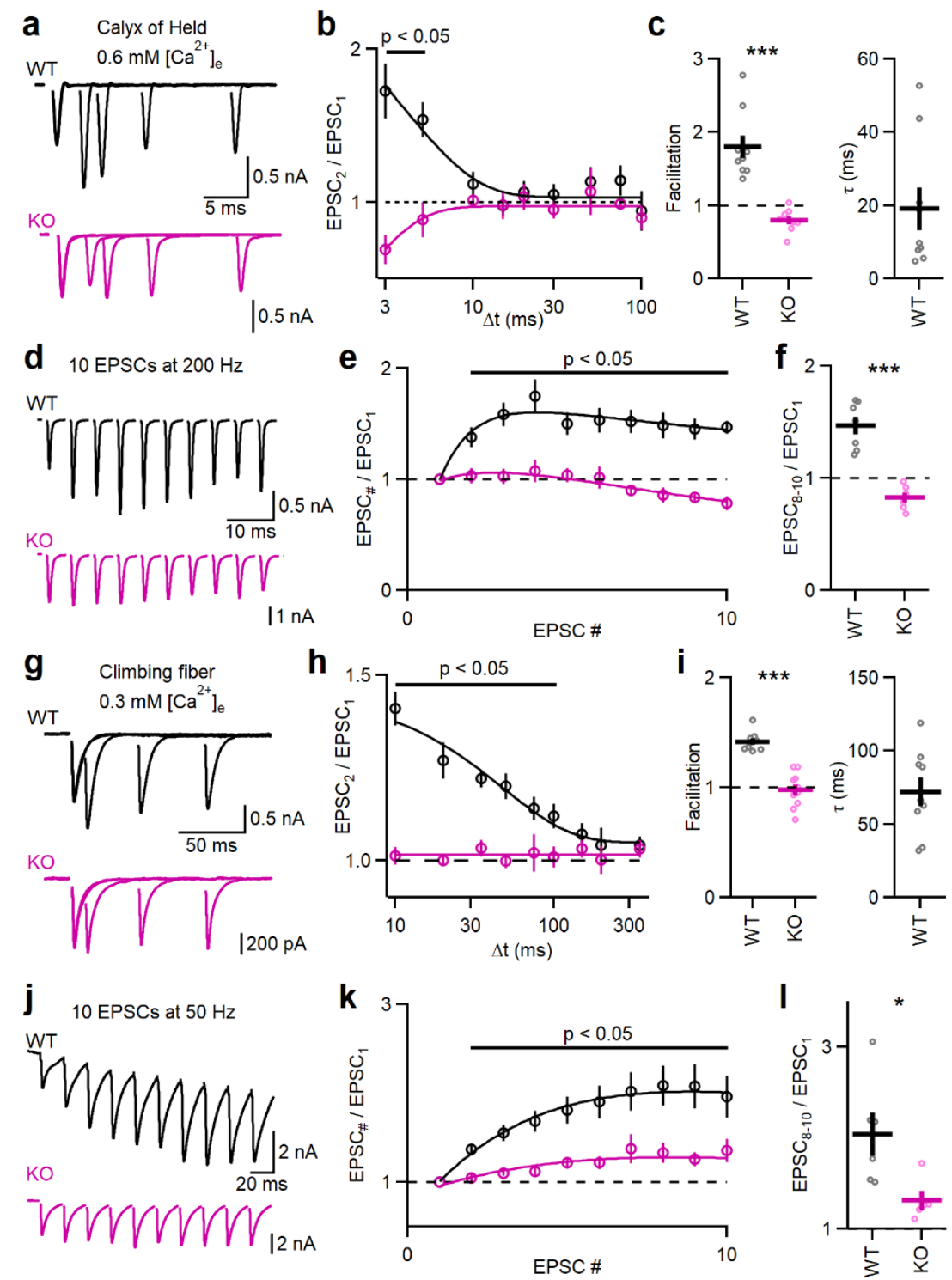

a) Superimposed recordings of EPSCs evoked by pairs of stimuli at the calyx of Held at varying intervals $(\Delta t)$ in $0.6 \mathrm{mM}\left[\mathrm{Ca}^{2+}\right]_{\mathrm{e}}$.

b) Average paired-pulse ratios at the calyx of Held in $0.6 \mathrm{mM}\left[\mathrm{Ca}^{2+}\right]_{\mathrm{e}}$ fit exponentially.

c) Average magnitude and time constant of exponential fits to data in $b$.

d) Representative EPSCs at the calyx of Held evoked by stimulation at $200 \mathrm{~Hz}$.

e) Average normalized EPSCs during $200 \mathrm{~Hz}$ stimulation.

f) Normalized amplitude of the last 3 EPSCs $\left(\right.$ EPSC $\left._{8-10}\right)$ during $200 \mathrm{~Hz}$ stimulation.

g) Superimposed recordings of EPSCs evoked by pairs of stimuli at the calyx of Held at varying $\Delta \mathrm{t}$ in $0.3 \mathrm{mM}$ $\left[\mathrm{Ca}^{2+}\right]_{\mathrm{e}}$.

h) Paired-pulse ratios in climbing fibers in $0.3 \mathrm{mM}\left[\mathrm{Ca}^{2+}\right]_{\mathrm{e}}$ fit exponentially.

i) Average magnitude and time constant of exponential fits to data in $\mathrm{h}$.

j) Representative EPSCs evoked by climbing fiber stimulation at $50 \mathrm{~Hz}$.

k) Average normalized amplitudes of climbing fiber EPSCs during $50 \mathrm{~Hz}$ stimulation.

l) Normalized amplitude of the last 3 EPSCs (EPSC $8-10)$ during $50 \mathrm{~Hz}$ stimulation. 
bioRxiv preprint doi: https://doi.org/10.1101/2021.09.27.462028; this version posted September 27, 2021. The copyright holder for this preprint (which was not certified by peer review) is the author/funder, who has granted bioRxiv a license to display the preprint in perpetuity. It is made available under aCC-BY 4.0 International license.

\section{Extended data}

Extended Data Fig. 1 | Immunolabeling for SYT3 in WT and knockout animals

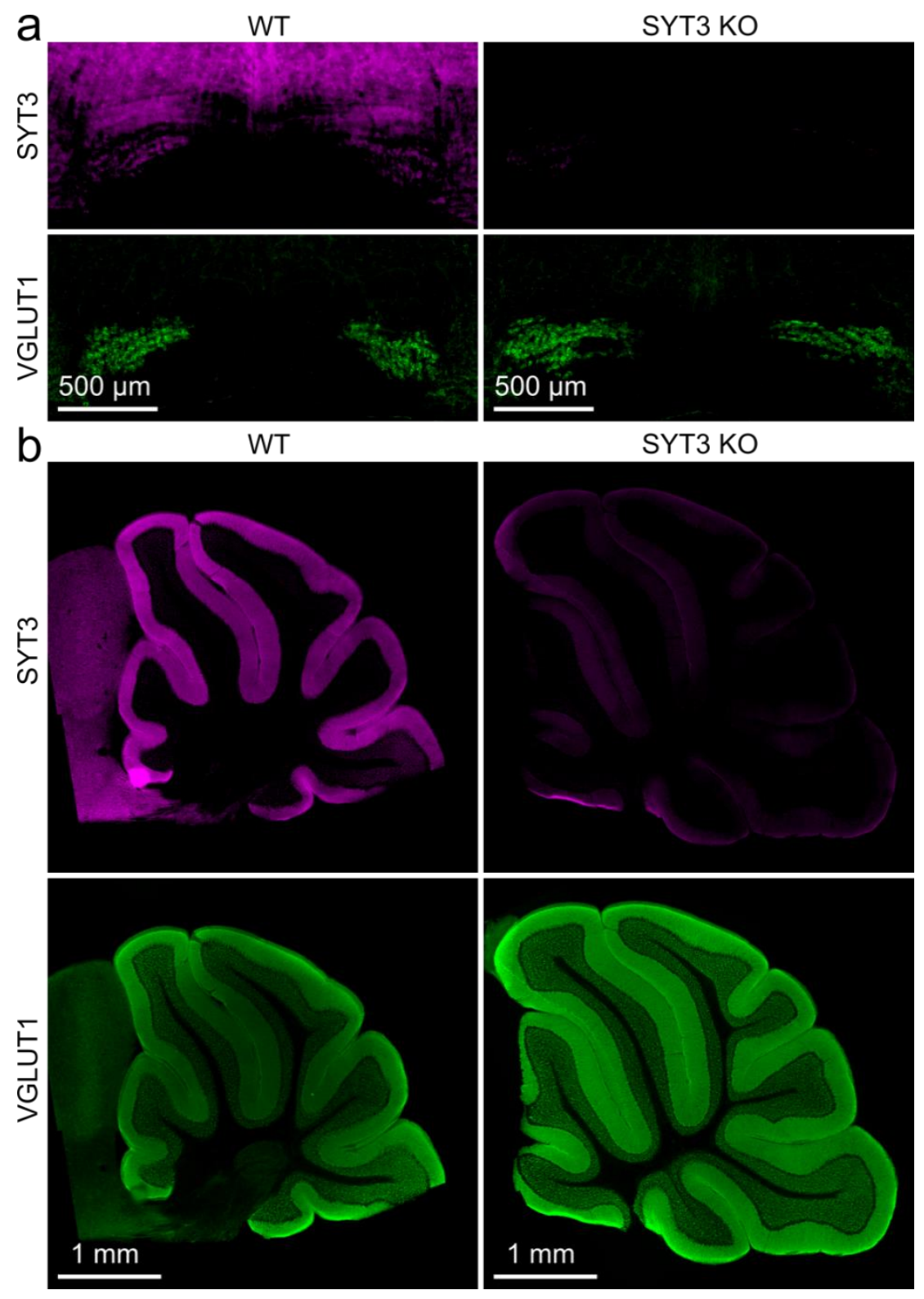

a-b) Fluorescent images showing immunolabeling for SYT3 and VGLUT1 in the brainstem (a) and cerebellum (b) of WT and Syt3 KOs. 
Extended Data Fig. 2 | Basal synaptic properties are unchanged in Syt3 knockouts

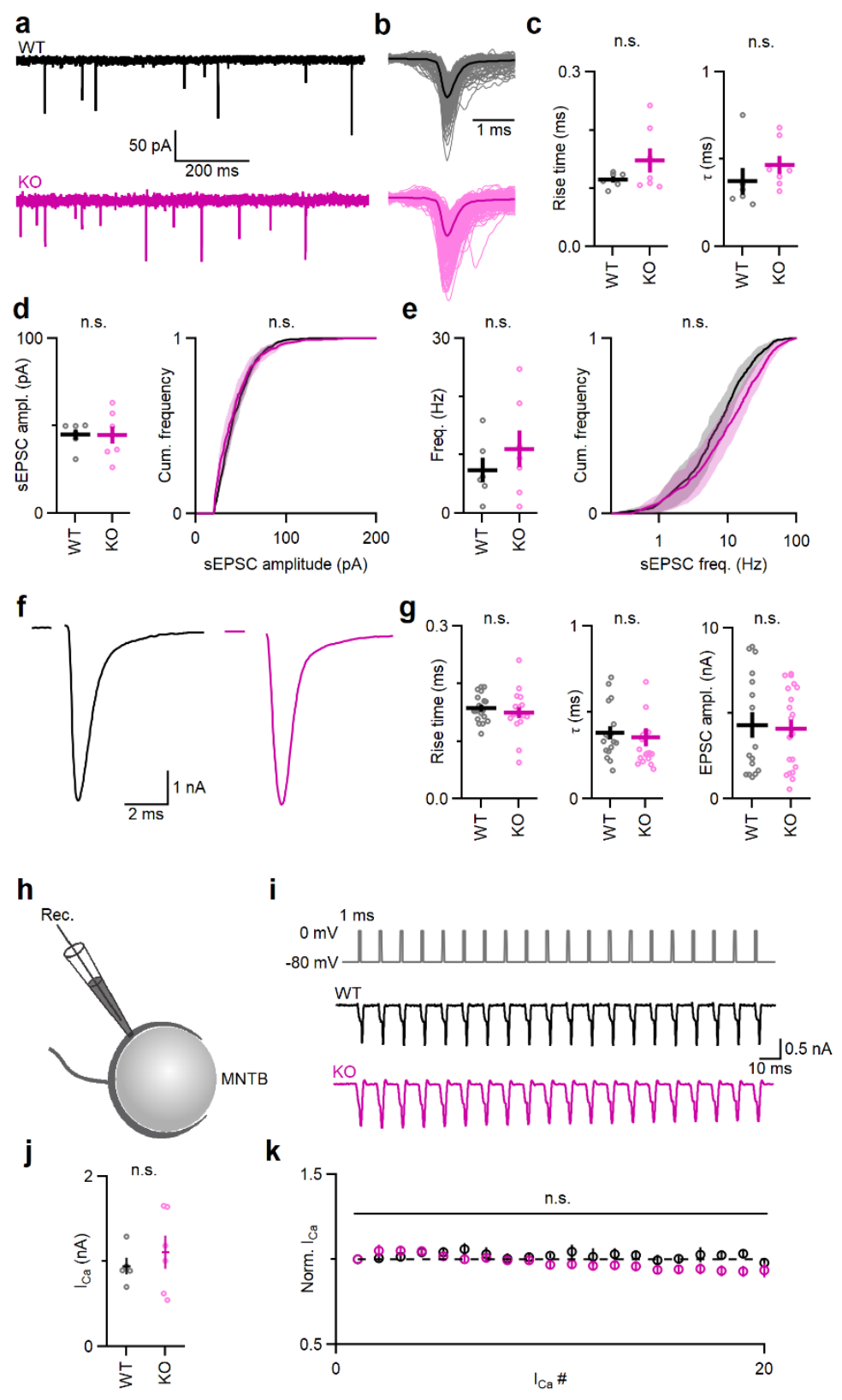

a) Representative spontaneous excitatory postsynaptic currents (sEPSCs) recorded from MNTB neurons in WT (black) and Syt3 KO animals (magenta).

b) Averaged sEPSC waveforms.

c) Average rise and decay time constants of sEPSCs.

d) Average and cumulative distribution of sEPSC amplitudes.

e) Average and cumulative distribution of sEPSC frequency.

f) Representative EPSCs elicited by afferent fiber stimulation of the calyx of Held.

g) Average rise and decay time constants, and amplitudes of EPSCs.

h) Schematic showing presynaptic $\mathrm{Ca}^{2+}$-current $\left(\mathrm{I}_{\mathrm{Ca}}\right)$ recordings at the calyx of Held.

i) $\mathrm{I}_{\mathrm{Ca}}$ elicited by $1 \mathrm{~ms}$ depolarizations from $-80 \mathrm{mV}$ to $0 \mathrm{mV}$ at $100 \mathrm{~Hz}$.

j) Average amplitudes of initial $\mathrm{I}_{\mathrm{Ca}}$.

k) Normalized $\mathrm{I}_{\mathrm{Ca}}$ evoked by 20 depolarization steps at $100 \mathrm{~Hz}$. 
Extended Data Fig. 3 | The readily releasable pool of vesicles is decreased in Syt3 knockouts
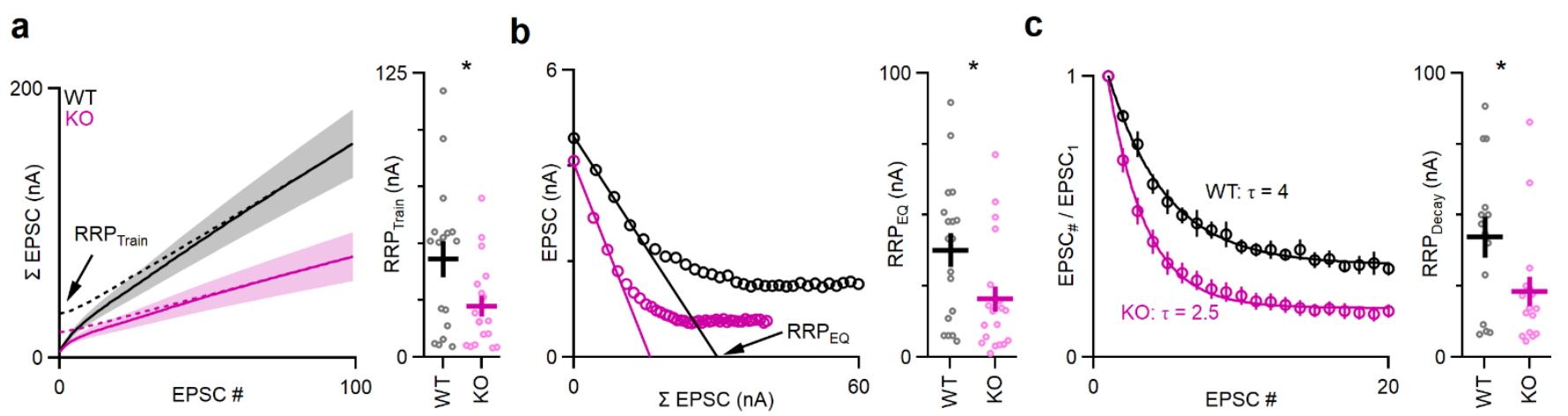

a) Averaged cumulative amplitudes of EPSCs elicited by $200 \mathrm{~Hz}$ stimulation at the calyx of Held in WT (black) and Syt3 KO (magenta) animals. Back-extrapolation from EPSC $81-100{ }^{25}$ corrected for vesicle replenishment early in the $\operatorname{train}^{27}$ was used to estimate the RRP Train.

b) Amplitudes of the first 40 EPSCs at $200 \mathrm{~Hz}$ stimulation plotted against cumulative release. Linear forwardextrapolation of the first 4 EPSCs was used to estimate the RRPEQ ${ }^{28}$.

c) Normalized amplitudes of the first 20 EPSCs at $200 \mathrm{~Hz}$ stimulation. $\tau_{\text {Decay }}$ was calculated with a single exponential fit. $R$ RPPecay was estimated from $\tau_{\text {Decay }}{ }^{29}$. 
Extended Data Figure 4| Biophysical models of SYT3 at the calyx of Held

a

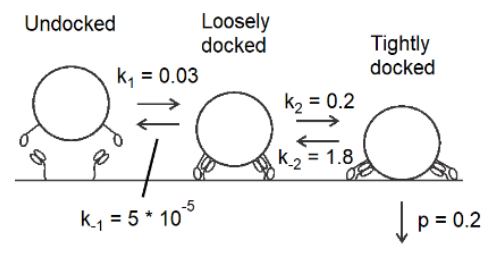

C

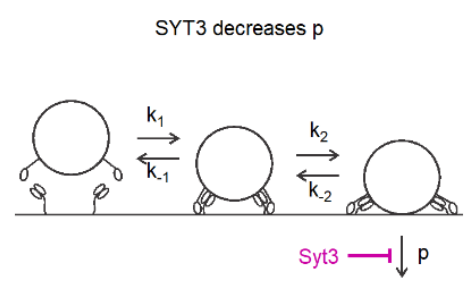

e

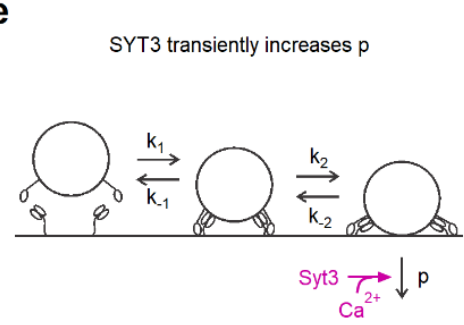

g

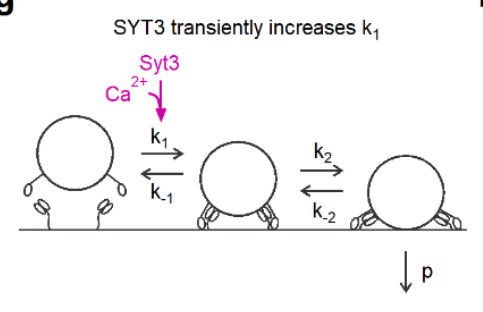

i

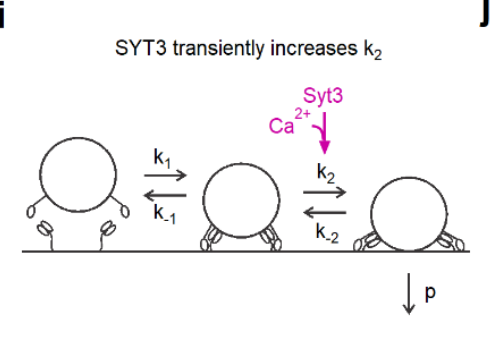

b

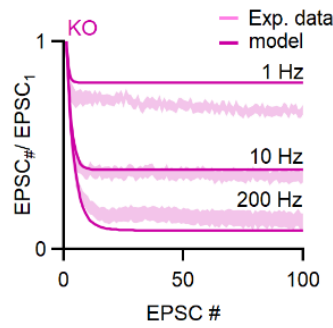

d

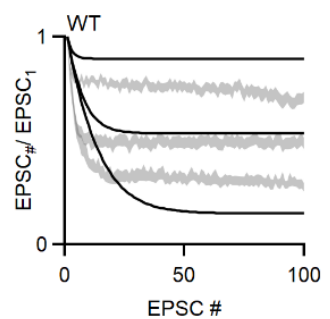

f

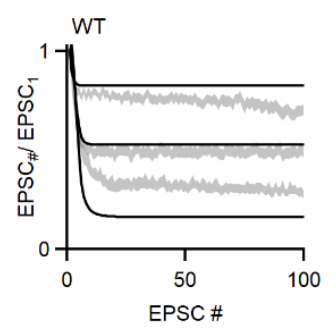

h

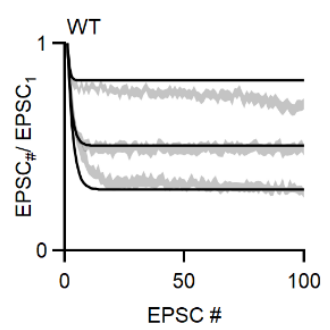

j

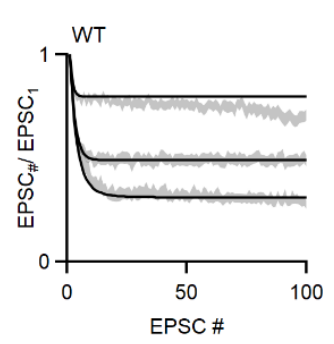

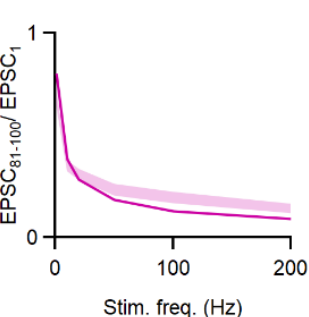
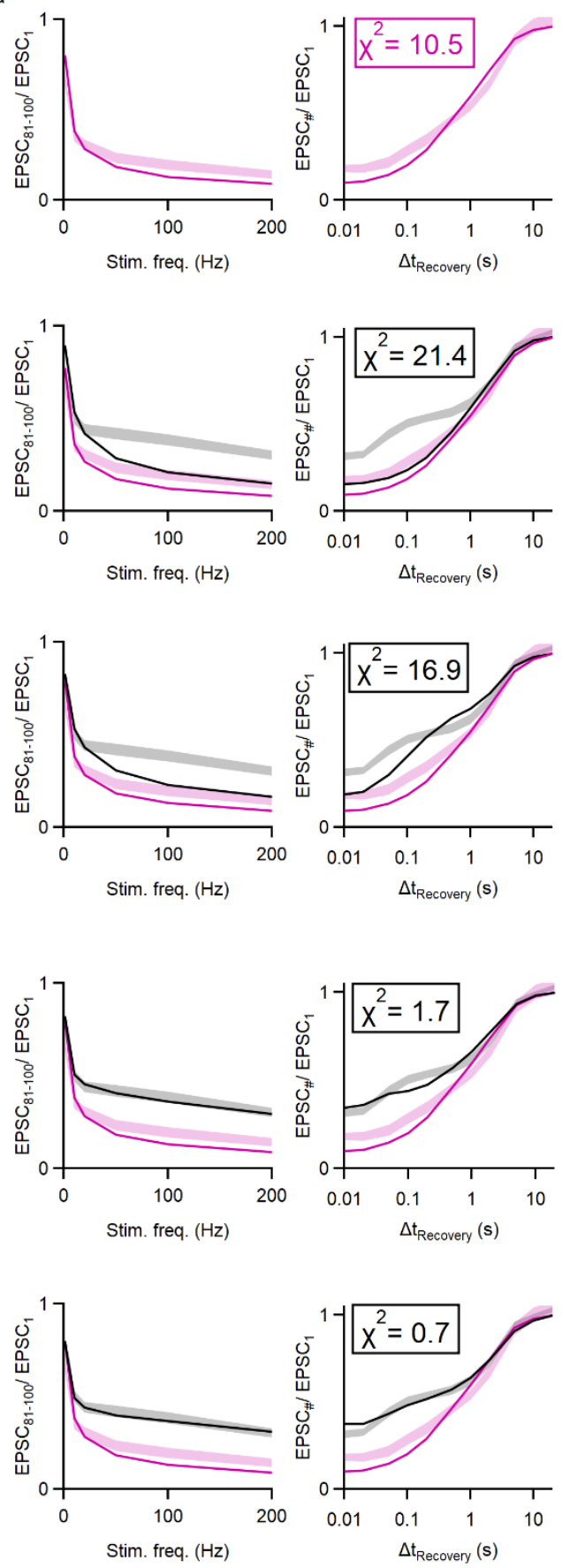

a) Illustrated model of vesicle docking and fusion based on previous studies ${ }^{4,47}$ (see Methods). An infinite pool of reserve vesicles reversibly transitions to a fusion-incompetent loosely docked state. Loosely docked vesicles reversibly transition to a fusion-competent tightly docked state, and release with a fixed probability (p). For the conceptual basis of this model, $\mathrm{see}^{30}$. Rates determined by fitting the model to KO data are shown in $\mathrm{ms}^{-1}$. 
b) Best fit of the model (magenta) to Syt3 KO data (light magenta) for EPSC trains (left), steady-state amplitudes for frequencies from $1-200 \mathrm{~Hz}$ (center), and recovery from depression after $100 \mathrm{EPSCs}$ at $200 \mathrm{~Hz}$ (right).

c) Illustration of a model where SYT3 reduces vesicle depletion by permanently lowering $p$, as has been suggested for other synaptotagmin isoforms ${ }^{48}$.

d) Best fit of the model shown in c (black) to data (gray) for WT calyces of Held.

e) A model where SYT3 increases p immediately after each action potential, after which p decreases exponentially back to its baseline value.

f) Best fit of the model shown in e to WT data.

g) A model where SYT3 transiently increases $k_{1}$. After each action potential $\mathrm{k}_{1}$ increases by a fixed amount, after which $\mathrm{k}_{1}$ decreases exponentially back to its baseline value.

h) Best fit of the model shown in $\mathrm{g}$ to WT data.

i) A model where SYT3 transiently increases $\mathrm{k}_{2}$. After each action potential $\mathrm{k}_{2}$ increases by a fixed amount, after which $\mathrm{k}_{2}$ decreases exponentially back to its baseline value.

j) Best fit of the model shown in i to WT data. Note that this model produced the lowest $\chi^{2}$ values among all models tested, supporting a scenario where SYT3 accelerates the transition of vesicles to a tightly docked state. 
Extended Data Figure 5| Recovery from depression is slowed by loss of Syt3 at cerebellar mossy fiber synapses
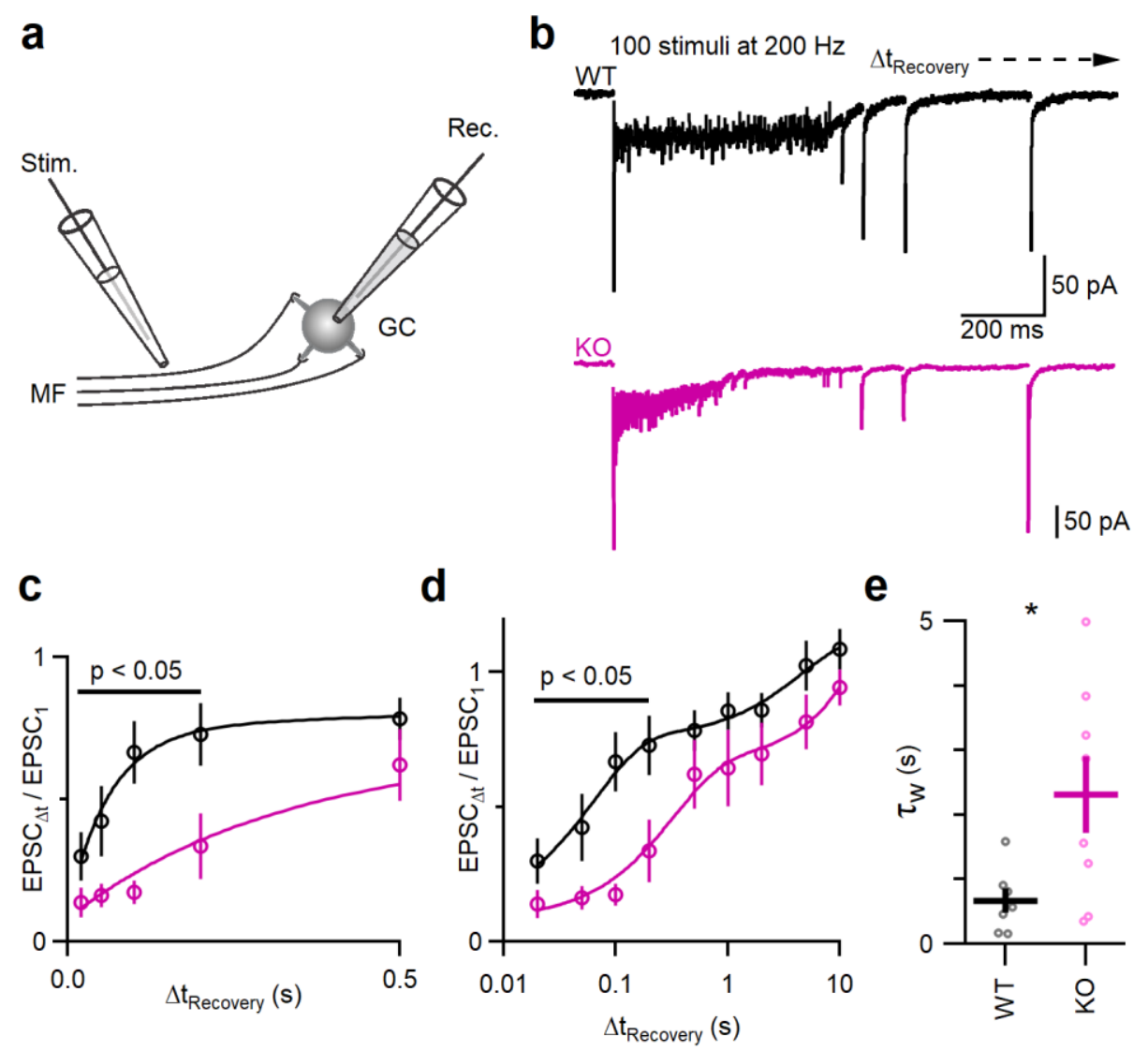

a) Schematic of cerebellar mossy fiber recordings. EPSCs were recorded from voltage-clamped granule cells (GC) while mossy fibers (MF) were activated by electrical stimulation in the white matter 50-100 $\mu \mathrm{m}$ from the cell.

b) Representative EPSCs elicited by 100 stimuli at $200 \mathrm{~Hz}$, followed by stimuli at varying intervals to probe recovery from depression $\left(\Delta t_{\text {Recovery }}\right)$

c-d) Time course of recovery of EPSCs in the first $0.5 \mathrm{~s}$ after trains (c, linear scale) and $10 \mathrm{~s}$ (d, logarithmic scale).

e) Weighted time constants of biexponential recovery $\left(\tau_{w}\right)$. 


\section{Tables}

Table 1 | Number of recordings from wild-type and Syt3 KO animals

\begin{tabular}{|c|c|c|c|c|c|}
\hline Figure & Synapse/Region & Experiment & Sample & \# of recordings & \# of animals \\
\hline \multirow[t]{2}{*}{ Figure 1e } & \multirow[t]{2}{*}{$\begin{array}{l}\text { Brainstem/ } \\
\text { Cerebellum }\end{array}$} & \multirow[t]{2}{*}{$\begin{array}{l}\text { Synaptosome } \\
\text { immunolabeling }\end{array}$} & Brainstem & 10 & $\begin{array}{l}6 \text { (pooled to } 1 \\
\text { sample) }\end{array}$ \\
\hline & & & Cerebellum & 10 & $\begin{array}{l}6 \text { (pooled to } 1 \\
\text { sample) }\end{array}$ \\
\hline \multirow[t]{2}{*}{ Figure $2 c$} & \multirow[t]{2}{*}{ Calyx of Held } & \multirow[t]{2}{*}{ Charge transfer } & WT & 15 & 5 \\
\hline & & & $\mathrm{KO}$ & 18 & 5 \\
\hline \multirow[t]{4}{*}{ Figure $2 d-g$} & \multirow[t]{4}{*}{ Calyx of Held } & \multirow{4}{*}{$\begin{array}{l}\text { Recovery from } \\
\text { depression }\end{array}$} & WT & 18 & 5 \\
\hline & & & WT-EGTA & 6 & 2 \\
\hline & & & $\mathrm{KO}$ & 20 & 5 \\
\hline & & & KO-EGTA & 6 & 2 \\
\hline \multirow[t]{3}{*}{ Figure 3d-e } & \multirow[t]{3}{*}{ Calyx of Held } & \multirow[t]{3}{*}{ Viral rescue } & GFP-negative & 7 & 3 \\
\hline & & & Syt3 ${ }^{\mathrm{WT}}$ rescue & 10 & 4 \\
\hline & & & Syt3 ${ }^{\mathrm{D} / \mathrm{N}}$ rescue & 6 & 2 \\
\hline \multirow[t]{2}{*}{ Figure $4 b-c$} & \multirow[t]{2}{*}{ Climbing fiber } & \multirow[t]{2}{*}{ EPSC kinetics } & WT & $17-18$ & 7 \\
\hline & & & $\mathrm{KO}$ & $14-15$ & 6 \\
\hline \multirow[t]{4}{*}{ Figure $4 d-i$} & \multirow[t]{4}{*}{ Climbing fiber } & \multirow{4}{*}{$\begin{array}{l}\text { Recovery from } \\
\text { depression }\end{array}$} & WT & 13 & 7 \\
\hline & & & WT-EGTA & 13 & 4 \\
\hline & & & $\mathrm{KO}$ & 12 & 6 \\
\hline & & & KO-EGTA & 10 & 5 \\
\hline \multirow{2}{*}{ Figure 5a-c } & \multirow{2}{*}{ Calyx of Held } & \multirow{2}{*}{$\begin{array}{l}\text { Low }\left[\mathrm{Ca}^{2+}\right]_{\mathrm{e}} \\
\text { paired-pulse ratio }\end{array}$} & WT & 9 & 3 \\
\hline & & & $\mathrm{KO}$ & 8 & 3 \\
\hline \multirow[t]{2}{*}{ Figure 5d-f } & \multirow[t]{2}{*}{ Calyx of Held } & \multirow{2}{*}{$\begin{array}{l}\text { Low }\left[\mathrm{Ca}^{2+}\right]_{\mathrm{e}} \\
\text { trains }\end{array}$} & WT & 7 & 3 \\
\hline & & & $\mathrm{KO}$ & 6 & 3 \\
\hline \multirow[t]{2}{*}{ Figure 5g-i } & \multirow[t]{2}{*}{ Climbing fiber } & \multirow{2}{*}{$\begin{array}{l}\text { Low }\left[\mathrm{Ca}^{2+}\right]_{\mathrm{e}} \\
\text { paired-pulse ratio }\end{array}$} & WT & 9 & 2 \\
\hline & & & $\mathrm{KO}$ & 10 & 2 \\
\hline \multirow[t]{2}{*}{ Figure $5 \mathrm{j}-1$} & Climbing fiber & Low $\left[\mathrm{Ca}^{2+}\right]_{\mathrm{e}}$ & WT & 6 & 2 \\
\hline & & trains & $\mathrm{KO}$ & 5 & 2 \\
\hline Extended Data & Calyx of Held & sEPSC kinetics & WT & 6 & 2 \\
\hline Figure 2 a-e & & & $\mathrm{KO}$ & 7 & 2 \\
\hline Extended Data & Calyx of Held & EPSC kinetics & WT & $16-17$ & 5 \\
\hline Figure $2 \mathrm{f}-\mathrm{g}$ & & & $\mathrm{KO}$ & $18-20$ & 5 \\
\hline Extended Data & Calyx of Held & Presynaptic Ca- & WT & 5 & 2 \\
\hline Figure 2 h-k & & currents & $\mathrm{KO}$ & 6 & 2 \\
\hline Extended Data & Calyx of Held & RRP estimation & WT & $16-17$ & 5 \\
\hline Figure 3 & & & $\mathrm{KO}$ & $14-20$ & 5 \\
\hline Extended Data & Mossy fiber & Recovery from & WT & 7 & 4 \\
\hline Figure 5 & & depression & $\mathrm{KO}$ & 8 & 5 \\
\hline
\end{tabular}

